\title{
CRISTA-NF measurements during the AMMA-SCOUT-O3 aircraft campaign
}

\author{
K. Weigel ${ }^{1, *}$, M. Riese ${ }^{1,2}$, L. Hoffmann ${ }^{1}$, S. Hoefer ${ }^{1}$, C. Kalicinsky ${ }^{2}$, P. Knieling ${ }^{2}$, F. Olschewski ${ }^{2}$, P. Preusse ${ }^{1}$, \\ R. Spang ${ }^{1}$, F. Stroh ${ }^{1}$, and C. M. Volk ${ }^{2}$ \\ ${ }^{1}$ Institute of Chemistry \& Dynamics of the Geosphere (ICG-1), Forschungszentrum Jülich, 52425 Jülich, Germany \\ ${ }^{2}$ Department of Physics, University of Wuppertal, 42907 Wuppertal, Germany \\ *now at: Institute of Environmental Physics (IUP), University of Bremen, 28359 Bremen, Germany
}

Received: 10 February 2010 - Published in Atmos. Meas. Tech. Discuss.: 9 March 2010

Revised: 12 September 2010 - Accepted: 17 September 2010 - Published: 13 October 2010

\begin{abstract}
The Cryogenic Infrared Spectrometers and Telescopes for the Atmosphere - New Frontiers (CRISTA-NF) instrument participated in the AMMA-SCOUT-O3 measurement campaign in July and August 2006. The instrument is mounted on the high-flying Russian research aircraft M55-Geophysica and measures limb-emissions in the midinfrared region in the tangent altitude range of about 6 to $21 \mathrm{~km}$. We present a new retrieval setup which is based on 9 integrated spectral windows allowing to retrieve an extended set of trace gases and temperature fields with high vertical resolution (up to $500 \mathrm{~m}$ ). Retrieval results are shown for temperature, water vapor $\left(\mathrm{H}_{2} \mathrm{O}\right)$, ozone $\left(\mathrm{O}_{3}\right)$, nitric acid $\left(\mathrm{HNO}_{3}\right)$, peroxyacetyl nitrate (PAN), carbon tetrachloride $\left(\mathrm{CCl}_{4}\right)$, and aerosol extinction. Comparisons of temperature, $\mathrm{O}_{3}$, and $\mathrm{H}_{2} \mathrm{O}$ observations with corresponding in situ measurements on-board M55-Geophysica show reasonable agreement. In particular, CRISTA-NF observations in the vicinity of the aircraft resemble horizontal variations found in the in situ measurements better than corresponding ECMWF fields.
\end{abstract}

\section{Introduction}

The upper troposphere/lower stratosphere (UTLS) plays a key role in the climate system. Changes in the structure and chemical composition of this region result in particularly large changes in the radiative forcing of the atmosphere, which trigger climate change. In spite of its immense

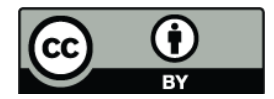

Correspondence to: $\mathrm{K}$. Weigel (weigel@iup.physik.uni-bremen.de) significance, the UTLS is one of the least understood regions of the atmosphere. This is a result of its great dynamical, chemical, and micro-physical complexity. This applies, for example, to stratosphere-troposphere-exchange of trace gases, which has a strong impact on the structure and chemical composition of the UTLS (e.g. Holton et al., 1995). Unfortunately, the UTLS is only sparsely covered by in situ measurements and not well resolved by satellite observations (e.g. Engel et al., 2006).

The Cryogenic Infrared Spectrometers and Telescopes for the Atmosphere - New Frontiers (CRISTA-NF) limbobservations of atmospheric infrared-emissions provide the opportunity to derive profile information with high spatial sampling in the UTLS for a variety of trace substances. The instrument is mounted on the high-flying Russian research aircraft M55-Geophysica, which reaches flight altitudes up to $21 \mathrm{~km}$ (Stefanutti et al., 1999). The CRISTA-NF optics are adapted from optical system of the Space Shuttle experiment CRISTA that was successfully flown aboard the Shuttle Pallet Satellite SPAS in November 1994 [STS 66] and August 1997 [STS 85] (Offermann et al., 1999; Grossmann et al., 2002).

In this paper, we present CRISTA-NF observations, which were made during the Special Observation Period of the African Monsoon Multidisciplinary Analyses (AMMA) campaign (Redelsperger et al., 2006), which was performed in cooperation with the Stratosphere-Climate links with emphasis On the UTLS-O 3 (SCOUT-O3) project (Cairo et al., 2010). CRISTA-NF participated in ten M55-Geophysica flights: a test flight over Italy (hereafter TF2), four transfer flights between Oberpfaffenhofen (Germany) and the main campaign site in Ouagadougou, Burkina Faso, Africa

Published by Copernicus Publications on behalf of the European Geosciences Union. 
(hereafter T1-T4), and five local flights from Ouagadougou (hereafter L1-L5), which is located at $4^{\circ} \mathrm{W}$ and $12^{\circ} \mathrm{N}$. Here, we focus on results obtained for the local flight L5 (13 August 2006). Flight L5 was chosen because on this flight CRISTA-NF has the best data quality of all local flights (i.e. fewest clouds and no complicated flight maneuvers). We decided to focus on a local flight because the main focus of the AMMA campaign and hence the in situ measurements was on the local flights. In particular we present a detailed characterization of our the retrieval approach and comparisons with simultaneous in situ measurements.

Section 2 gives a brief overview on the CRISTA-NF instrument and its spatial and spectral sampling characteristics. In Sect. 3, we introduce our radiative transfer scheme that allows fast and accurate forward calculations based on precalculated atmospheric emissivity tables. The new retrieval scheme uses 9 ISWs from channel L6, in contrary to the retrieval scheme presented by Hoffmann et al. (2009), which uses 3 ISWs from channel H5. The higher number of ISWs from a wider spectral range allows us to retrieve not only water vapor volume mixing ratios, aerosol extinction, tangent heights and radiometric offset as in Hoffmann et al. (2009) but additionally $\mathrm{O}_{3}, \mathrm{HNO}_{3}, \mathrm{PAN}, \mathrm{CCl}_{4}$ and temperature. An overview on the retrieval scheme is given in Sect. 4 with emphasis on the retrieval grid, the determination of tangent heights from CRISTA-NF radiance measurements, a priori information used for the retrieval, achievable vertical resolution, measurement contribution, and error analysis. Retrieved distributions of temperature and volume mixing ratios of water vapor $\left(\mathrm{H}_{2} \mathrm{O}\right)$, ozone $\left(\mathrm{O}_{3}\right)$, nitric acid $\left(\mathrm{HNO}_{3}\right)$, peroxyacetyl nitrate (PAN), carbon tetrachloride $\left(\mathrm{CCL}_{4}\right)$, and aerosol extinction for two fights are presented in Sect. 5 . A comparison of observed temperature $\mathrm{H}_{2} \mathrm{O}$, and $\mathrm{O}_{3}$ values with corresponding in situ measurements is also presented in Sect. 5.

\section{The CRISTA-NF instrument}

CRISTA-NF measures thermal emissions ( 4 to $15 \mu \mathrm{m}$ ) of selected trace gases with a dense vertical sampling. The instrument is mounted on the high-flying Russian research aircraft M55-Geophysica. First observations of the CRISTANF instrument on-board M55-Geophysica were made during the SCOUT-O3 tropical aircraft campaign in autumn 2005 (Hoffmann et al., 2009; Spang et al., 2008; Kullmann, 2006).

CRISTA-NF uses a Herschel telescope with a tiltable mirror to scan the atmosphere from the flight altitude of the aircraft (up to $21 \mathrm{~km}$ ) down to about $6 \mathrm{~km}$ with a vertical sampling step of about $250 \mathrm{~m}$ (60 vertical steps). The tangent point moves away from the aircraft with decreasing tangent height. The horizontal distance of the tangent point from the aircraft is about $200 \mathrm{~km}$ at $10 \mathrm{~km}$ tangent height for the highest flight altitudes of the aircraft. Measurement time for one spectrum (tangent point) is about $1.2 \mathrm{~s}$ that means a complete altitude profile is recorded in about $70 \mathrm{~s}$. CRISTA-NF views perpendicular to the flight direction. The measurement time results in a horizontal distance between subsequent altitude profiles along the flight direction of about $15 \mathrm{~km}$, depending on the speed of the aircraft. The horizontal resolution along the line of sight is coarser (see e.g. von Clarmann et al., 2009). It dependents on the vertical resolution, the vertical distance to the aircraft altitude and the atmospheric refraction. In can be in the order up to of several $100 \mathrm{~km}$.

The incoming radiance is spectrally analyzed by two Ebert Fastie grating spectrometers (see e.g. Fastie, 1991) that contain a number of Si:Ga semi-conductor detectors. The scanning direction of the gratings is changed after each spectral scan. High measurement speed and consequently high spatial sampling is achieved by Helium-cooling of the optical system and detectors. Helium-cooling also results in an excellent signal-to-noise ratio of the limb-observations and sufficient suppression of self-emissions of the instrument. The atmospheric limb-radiance enters the optical system trough a zinc selenide $(\mathrm{ZnSe})$ window and passes several stray light baffles and an aperture that constrains the line of sight (LOS) to a beam of $5^{\prime \prime}$ in the vertical and $30^{\prime \prime}$ in the horizontal direction (perpendicular to the LOS). This results in a field of view (FOV) of approximately $300 \mathrm{~m}$ at about $10 \mathrm{~km}$ tangent height (see Spang et al., 2008).

Detailed descriptions of the CRISTA-NF optical system and radiometric calibration procedures are given by Kullmann et al. (2004); Kullmann (2006) and Schroeder et al. (2009), respectively. Here, we concentrate on measurements made by a specific detector channel of the "Low Resolution Spectrometer" covering the spectral region from 776 to $868 \mathrm{~cm}^{-1}$ (detector LRS6). The spectral resolving power is about $\lambda / d \lambda=500$ for this spectrometer. Figure 1 shows spectra measured by this detector during the flight on $13 \mathrm{Au}-$ gust 2006 during the AMMA campaign.

An important prerequisite for the retrieval is to filter the data for clouds and optically thick conditions. Therefore the cloud index is calculated as color ratio between the ISW from $791-793$ and $832-834 \mathrm{~cm}^{-1}$ at the measurement locations (see Spang et al., 2008). A cloud index lower than 3.5 is indicative for a significant influence of clouds (or optically thick conditions due to the water vapor continuum at the lowermost altitudes). Corresponding spectra are excluded from the retrieval. Figure 3 shows the cloud index of all flights where retrieval results are available with the scheme presented here.

\section{Fast radiative transfer model}

The fast measurement speed of CRISTA-NF results in a large amount of limb-radiance data. The retrieval must therefore be based on a fast forward model which is capable of simulating the limb-radiation received by the instrument along an LOS in viable CPU-time. In this work, we use the Juelich 


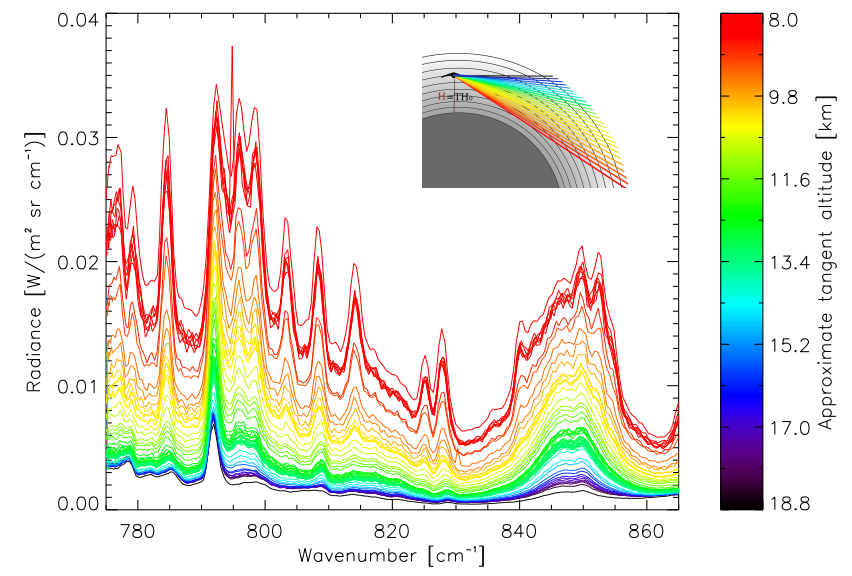

Fig. 1. Measured radiance spectra from detector LRS6 (776$868 \mathrm{~cm}^{-1}$ ) from profile 87 during the local flight L5. Color coding shows the approximate tangent altitude (without retrieval corrections and refraction).

Rapid Spectral Simulation Code (JURASSIC; Hoffmann, 2006; Hoffmann et al., 2009) that is applicable for satellite limb and nadir geometries (e.g. Hoffmann et al., 2008; Hoffmann and Alexander, 2009). The fast radiative transfer code of JURASSIC is based on emissivity look-up tables that are pre-calculated by the detailed line-by-line MIPAS reference forward model (RFM) (Dudhia et al., 2002). The RFM calculations are based on spectroscopic data taken from the HITRAN 2004 database (Rothman et al., 2005). For PAN spectroscopic data of Allen et al. (2005) are used. The RFM is well capable to simulate CRISTA-NF observations as shown in Fig. 2 for the spectral range covered by detector LRS6 (776-868 $\mathrm{cm}^{-1}$ ) and a tangent altitude of $12.6 \mathrm{~km}$. For the RFM, the measurement simulation is shown along with single gas contributions. This LRS6 detector channel covers a spectral range in the the atmospheric window region containing absorptions of various trace gases. The most distinct spectral features are the $\mathrm{CO}_{2}$ Q-branch at about $792 \mathrm{~cm}^{-1}$ and a CFC-11 band emission between about 840 and $860 \mathrm{~cm}^{-1}$.

For the fast forward model JURASSIC, we calculate integrated emissivities for 9 spectral windows in the spectral range of detector LRS6. The spectral position and the main targets for each integrated spectral window (hereafter ISW) are presented in Table 1 (see also Fig. 2 for the contributions of different emitters to the total radiance). Most ISW are chosen such that targeted trace gases are primary emitters in these spectral windows, i.e. the ISW from $784-785 \mathrm{~cm}^{-1}$ a significant fraction of the measured radiance is caused by $\mathrm{H}_{2} \mathrm{O}$ at lower altitudes. The same $\mathrm{H}_{2} \mathrm{O}$ line was used for the $\mathrm{H}_{2} \mathrm{O}$ retrieval for the CRISTA satellite experiment (Offermann et al., 2002; Schaeler and Riese, 2001). The $\mathrm{CO}_{2}$ Q-branch was previously used for the CRISTA temperature retrieval e.g. by Riese et al. $(1997,1999)$. The widths of the

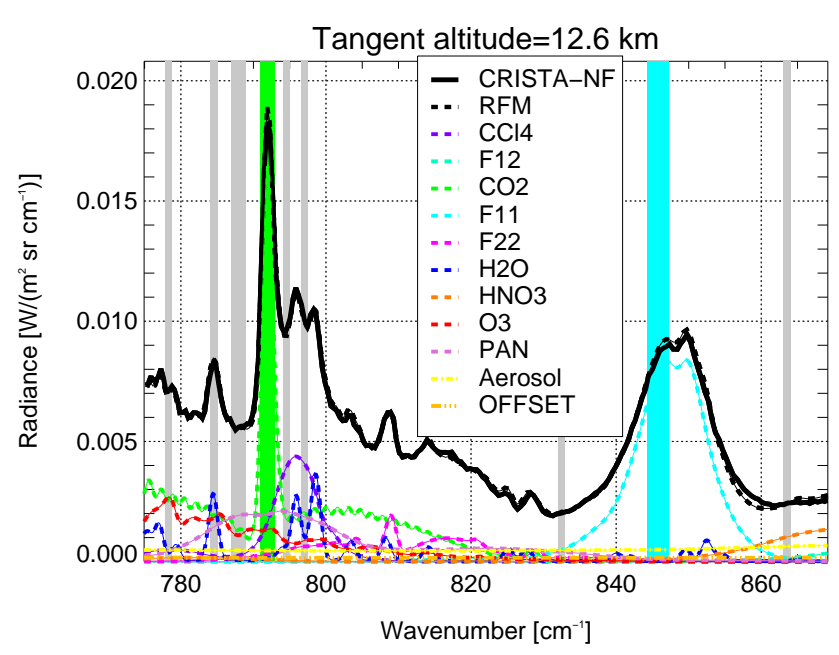

Fig. 2. CRISTA-NF spectra from detector LRS6, flight L5 profile 87 (black line). RFM calculation for the retrieval result is shown as black dashed line. Colored lines show the contribution of the most relevant trace gases to the result: $\mathrm{CO}_{2}$ (green), $\mathrm{O}_{3}$ (red), $\mathrm{H}_{2} \mathrm{O}$ (blue), CFC-11 (cyan), $\mathrm{HCFC}-22$ (pink), $\mathrm{HNO}_{3}$ (orange), $\mathrm{CCL}_{4}$ (violet) and PAN (orchid). The contribution of Aerosol is shown as yellow, the instruments radiance offset as gold line. Grey and colored bars indicate the position of the integrated spectral windows (ISWs) used for the retrieval. The ISWs dominated by CFC-11 and $\mathrm{CO}_{2}$ are highlighted in cyan and green, respectively.

Table 1. Integrated spectral bands (ISWs) used and main target variables.

\begin{tabular}{|c|c|}
\hline $\mathrm{ISW}\left[\mathrm{cm}^{-1}\right]$ & Main target \\
\hline $777.8-778.7$ & $\mathrm{O}_{3}$ \\
\hline $784-785$ & $\mathrm{H}_{2} \mathrm{O}$ \\
\hline $787-790$ & Offset \\
\hline $791-793$ & $\mathrm{CO}_{2}$ (Temperature/altitude) \\
\hline $794.1-795$ & PAN \\
\hline $796.6-797.5$ & $\mathrm{CCL}_{4}$ \\
\hline $832-832.9$ & Aerosol \\
\hline $844.3-847.3$ & CFC-11 (Temperature/altitude) \\
\hline $863-864$ & $\mathrm{HNO}_{3}$ \\
\hline
\end{tabular}

ISW are between 0.9 and $3 \mathrm{~cm}^{-1}$. The lower limit is chosen in order to have at least two spectral sampling points in each ISW (the CRISTA-NF spectral sampling for detector LRS6 is about $0.4 \mathrm{~cm}^{-1}$ ). The restriction to $3 \mathrm{~cm}^{-1}$ is driven by the need to minimize the influence of interfering species. The $787-790 \mathrm{~cm}^{-1}$ and $832-832.9 \mathrm{~cm}^{-1}$ ISW are located in spectral regions with rather low emissions to obtain information about aerosol (which has an almost continuum-like emission) and the radiometric offset, which can not be completely characterized by the black body calibration alone (see Sect. 4). 
Table 2. CRISTA-NF Level-2 data are available for the following AMMA flights.

\begin{tabular}{|c|c|c|c|c|}
\hline Abbr. & Date & Location & Main objective & Remark \\
\hline TF2 & $29 \mathrm{Jul} 2006$ & $\begin{array}{l}\text { From and } \\
\text { to Verona }\end{array}$ & $\begin{array}{l}\text { Instrument } \\
\text { test flight }\end{array}$ & $\begin{array}{l}\text { Active attitude system } \\
\text { used }\end{array}$ \\
\hline $\mathrm{T} 1$ & 31 Jul 2006 & $\begin{array}{l}\text { Verona } \\
\text { to Marrakesh }\end{array}$ & $\begin{array}{l}\text { Transfer } \\
\text { flight }\end{array}$ & \\
\hline $\mathrm{T} 2$ & 1 Aug 2006 & $\begin{array}{l}\text { Marrakesh } \\
\text { to Ouagadougou }\end{array}$ & $\begin{array}{l}\text { Transfer } \\
\text { flight }\end{array}$ & $\begin{array}{l}\text { Detector temperature } \\
\text { over } 14.5 \mathrm{~K} \text { (first } 1000 \mathrm{~s} \text { ) }\end{array}$ \\
\hline L5 & 13 Aug 2006 & $\begin{array}{l}\text { From and } \\
\text { to Ouagadougou }\end{array}$ & $\begin{array}{l}\text { CALIPSO }^{1} \\
\text { validation }\end{array}$ & $\begin{array}{l}\text { Detector temperature } \\
\text { over } 14.5 \mathrm{~K} \text { (first } 900 \mathrm{~s} \text { ) }\end{array}$ \\
\hline $\mathrm{T} 3$ & 16 Aug 2006 & $\begin{array}{l}\text { Ouagadougou } \\
\text { to Marrakesh }\end{array}$ & $\begin{array}{l}\text { Transfer } \\
\text { flight }\end{array}$ & \\
\hline $\mathrm{T} 4$ & 17 Aug 2006 & $\begin{array}{l}\text { Marrakesh } \\
\text { to Verona }\end{array}$ & $\begin{array}{l}\text { Transfer } \\
\text { flight }\end{array}$ & $\begin{array}{l}\text { Detector temperature } \\
\text { over } 14.5 \mathrm{~K} \text { (first } 2500 \mathrm{~s} \text { ) }\end{array}$ \\
\hline
\end{tabular}

${ }^{1}$ Cloud-Aerosol Lidar and Infrared Pathfinder Satellite Observation satellite (Winker et al., 2009).

For the fast radiative transfer calculations, the precalculated emissivity tables are utilized by approximate radiative transfer schemes. We use a combination of the emissivity growth approximation (EGA) (e.g. Gordley and Russell, 1981, Weinreb and Neuendorfer, 1973) and the CurtisGodson Approximation (CGA). These approximative methods provides good agreement with detailed line-by-line calculations in the stratosphere (e.g. Marshall et al., 1994). However, for applications in the troposphere, deviations from radiance values obtained from detailed line-by-line calculations sometimes exceeded 5 to $10 \%$. We therefore applied a linear regression model (see Hoffmann et al., 2009 and Weigel, 2009) to improve the agreement with line-by-line calculation to $0.2-0.8 \%$, depending on the wavelength. A similar approach was already successfully explored by Francis et al. (2006).

\section{Temperature and trace gas retrieval}

In the retrieval process, the received limb-radiance observations have to be inverted into an atmospheric state. Since the forward model is non-linear, there is no direct analytical way to calculate the composition of the atmosphere from the measured radiance. Hence, inverse methods must be used. This is done with the JURASSIC retrieval processor, which provides the maximum a posteriori solution (Rodgers, 2000) of the inverse problem. Trace gas volume mixing ratios, temperature, and aerosol extinction, which are varied during the retrieval process are called "retrieved" quantities or emitters. Trace gas mixing ratios, which are kept constant are called "forward model parameters" further on. In this study we apply a 1-D retrieval approach, i.e. individual limb scans of CRISTA-NF are analyzed separately, assuming a homogeneously stratified atmosphere. Further, we apply a

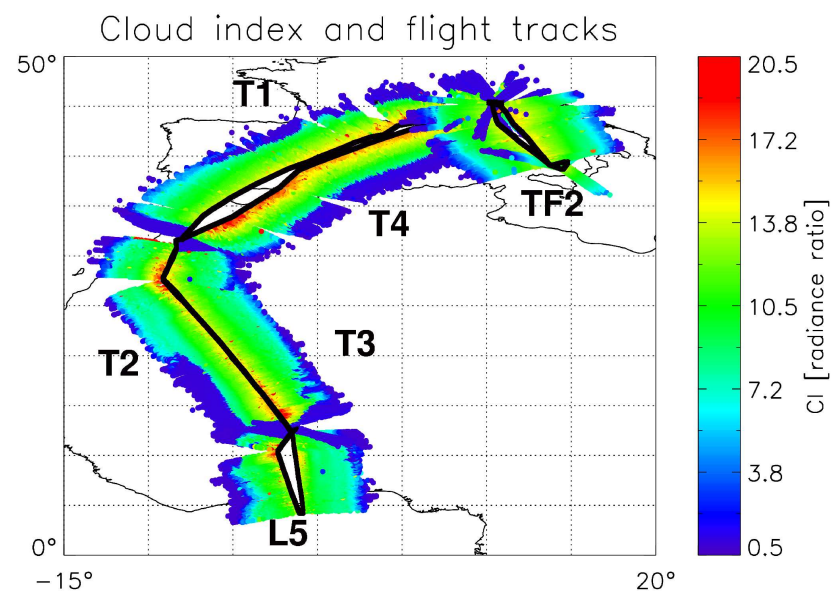

Fig. 3. Cloud index (CI) along the flight path for the transfer flights (T1-T4), the fifth local flight (L5) and the test flight (TF2) during the AMMA campaign. A CI lower than 3.5 (dark blue) indicates cloudy or optical dense conditions.

multi-target approach, i.e. all atmospheric quantities are retrieved simultaneously.

\subsection{A priori information}

Most a priori values of retrieved quantities and estimates of forward model parameters are taken from the MIPAS reference atmospheres (Remedios et al., 2007b). Carbon dioxide mixing ratios are particularly important forward model parameters, since they provide the basis for our temperature retrieval. For this reason, the 2001 values contained in the MIPAS reference atmosphere have been adjusted to 2006 conditions. Other modifications of forward model parameters are: CFC-113 is increased by a factor of 3.7 to achieve a better 
agreement with more recent measurements (e.g. Dufour et al., 2005 and Laube et al., 2008). CFC-113 is not one of our target trace gases (retrieved quantities), but we find that this adjustment improves the agreement between simulated and measured radiance values in the spectral regions where CFC113 emits. The PAN a priori value is set to zero in our retrieval approach, but an a priori standard deviation estimated from Glatthor et al. (2007) is used. Annual mean HCFC-22 values from the Atmospheric Chemistry Experiment Fourier Transform Spectrometer (ACE-FTS; see e.g. Bernath et al., 2005) are used. CFC-11 and CFC-12 profiles are combined from measurements of the High Altitude Gas Analyser (HAGAR) instrument (see e.g. Werner et al., 2009 and Homan et al., 2010) on-board the M55-Geophysica and values from Remedios et al. (2007b) for the upper altitudes.

A priori profiles for $\mathrm{O}_{3}$ and temperature are taken from European Centre for Medium-Range Weather Forecasts (ECMWF) operational analyses with 0.5 degrees horizontal resolution on 28 pressure levels interpolated on the vertical retrieval grid and position for each profile. Pressure is calculated from temperature and altitude assuming hydrostatic conditions using the ECMWF pressure as reference at $15 \mathrm{~km}$ altitude.

In addition to the absolute standard deviations from the climatology, percentage standard deviations constant for all altitudes have been defined, which are used if they exceed the climatological standard deviation. Rather conservative values are chosen for the standard deviation of the a priori information of the retrieved quantities in order to avoid a suppression of the information provided by the observation. More details about the selected a priori data can be found Tables 3 and 4 . Table 5 contains the errors for the measured radiances derived during the instrument calibration (Schroeder et al., 2009).

The a priori covariance for retrieved quantities is determined by a first-order autoregressive model (Rodgers, 2000):

$S_{i j}=\sigma_{i} \sigma_{j} \exp \left(-\Delta z / c_{\mathrm{Z}}\right)$,

where $\sigma_{i}$ is the standard deviation at altitude $z_{i}, \Delta z=$ $\left|z_{i}-z_{j}\right|$ is the vertical distance, and $c_{\mathrm{z}}$ is the correlation length. The correlation length determines the strength of the decay of the correlations in the a priori covariance. For each retrieved quantity the vertical correlation lengths can be chosen individually. For $\mathrm{O}_{3}$ and $\mathrm{HNO}_{3}$ long vertical correlation lengths $(100 \mathrm{~km})$ are found necessary to regularize the retrieval. These long correlation lengths are necessary to stabilize the retrieval for emitters with a high stratospheric abundance (i.e. $\mathrm{O}_{3}$ and $\mathrm{HNO}_{3}$ ) and correspond to a smoothness constraint (for the difference between the a priori and the retrieved profile) (Rodgers, 2000). For $\mathrm{CCL}_{4}$ and PAN a vertical correlation length of one kilometer is chosen, for $\mathrm{H}_{2} \mathrm{O}$ and temperature the vertical correlation length is set to $5 \mathrm{~km}$ and for aerosol to $25 \mathrm{~km}$. The choice of the correlation length may have significant influences on the the retrieval error and characteristics such as vertical resolution if the information content of the observations is poor. Otherwise it is found less important.

\subsection{Retrieval grid and tangent height determination}

Since part of the systematic error depends on the scanning direction of the gratings (see Riese et al., 1999) the spectra of each altitude scan are separated into two profiles, each containing spectra of one scanning direction of the grating only (hereafter "forward" and "backward" spectra). The resulting vertical sampling of the corresponding "forward" and "backward" profiles is approximately $500 \mathrm{~m}$. Therefore we chose a retrieval grid spacing of $500 \mathrm{~m}$ in the tangent altitude range. In our analysis, this retrieval grid was found to be a well-working pragmatic ad-hoc choice.

For an accurate simulation of the limb-radiance received by CRISTA-NF from the LOS, it is necessary to include information on the atmosphere above the highest tangent point because upper layers also contribute to the radiance received from the LOS. To account for this radiance contribution, a coarser vertical grid is sufficient. We therefore run the forward model on a vertical grid with 63 levels and a vertical step varying with altitude. The actual vertical spacing used in our analysis is as follows:

- $500 \mathrm{~m}$ spacing for altitudes between 3-20 km i.e. the region that covers the observations (tangent points).

- $1 \mathrm{~km}$ spacing for altitudes between $1-3 \mathrm{~km}$ and between $20-30 \mathrm{~km}$ i.e. in the vicinity of the altitude range covered by observations.

- $2 \mathrm{~km}$ spacing for altitudes between $30-50 \mathrm{~km}$.

- $2.5 \mathrm{~km}$ spacing for altitudes between $50-65 \mathrm{~km}$.

A 1-D-retrieval is run for each profile independently assuming a horizontal homogeneous atmosphere. However, information on the horizontal structure of the atmosphere can be obtained from successive profiles along the flight direction of the aircraft. The retrieval is run on selected altitude ranges of the retrieval grid depending on the retrieved quantities. The lowest altitude is $5 \mathrm{~km}$ for all retrieved quantities, the upper altitude varies between $17 \mathrm{~km}$ for $\mathrm{H}_{2} \mathrm{O}$ and aerosol extinction, $60 \mathrm{~km}$ for $\mathrm{HNO}_{3}$ and $\mathrm{O}_{3}$, and $25 \mathrm{~km}$ for the other retrieved quantities.

As discussed in Hoffmann et al. (2009), the tangent altitude cannot be determined with sufficient accuracy from the M55-Geophysica attitude system alone. Hence, it is retrieved simultaneously with the target trace gases, temperature and an radiometric offset. For the temperature and altitude retrieval we use the $\mathrm{CO}_{2}$ Q-branch at $792 \mathrm{~cm}^{-1}$ as well as the $845 \mathrm{~cm}^{-1}$ CFC-11 emission band (see Fig. 2).

Like $\mathrm{CO}_{2}$, which is commonly used for the retrieval of atmospheric temperature, the concentration of CFC-11 in the troposphere and lower stratosphere is sufficiently well known to accurately retrieve the altitude of the measurement. 
Table 3. Retrieved gases, aerosol and temperature.

\begin{tabular}{|c|c|c|c|c|}
\hline Emitter & $\begin{array}{l}\text { A priori } \\
\text { state }\end{array}$ & $\begin{array}{l}\text { Altitude dependent } \\
\text { dependent a priori } \\
\text { standard deviation }\end{array}$ & $\begin{array}{l}\text { Minimum } \\
\text { a priori standard } \\
\text { deviation }\end{array}$ & $\begin{array}{l}\text { Uncertainty } \\
\text { of spectros- } \\
\text { copic data }\end{array}$ \\
\hline $\mathrm{CCL}_{4}$ & global $^{1}$ & midlat./tropical ${ }^{1}$ & $1 \%$ & $2 \%$ \\
\hline $\mathrm{H}_{2} \mathrm{O}$ & midlat./tropical ${ }^{1}$ & $\begin{array}{l}200 \text { ppmV under, } \\
2 \text { ppmV over } 17 \mathrm{~km}\end{array}$ & $50 \%$ & $5 \%$ \\
\hline $\mathrm{HNO}_{3}$ & tropical $^{1}$ & 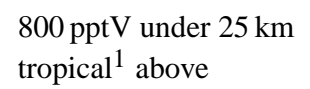 & $20 \%$ & $4.5 \%$ \\
\hline $\mathrm{O}_{3}$ & ECMWF & $300 \mathrm{ppbV}$ & $5 \%$ & $5 \%$ \\
\hline PAN & $\begin{array}{l}\text { set to } \\
\text { zero }\end{array}$ & $\begin{array}{l}100 \% \text { of approximated } \\
\text { profile from } \\
\text { (Glatthor et al., 2007) }\end{array}$ & $100 \%$ & $4 \%$ \\
\hline Aerosol & HALOE $^{2}$ & - & $500 \%$ & - \\
\hline Temperature & ECMWF & - & $5 \mathrm{~K}$ & - \\
\hline
\end{tabular}

${ }^{1}$ Remedios et al. (2007b), ${ }^{2}$ HALogen Occultation Experiment (Hervig et al., 1993)

Table 4. Forward model parameters.

\begin{tabular}{|c|c|c|c|c|}
\hline $\begin{array}{l}\text { Para- } \\
\text { meter }\end{array}$ & $\begin{array}{l}\text { A priori } \\
\text { state }\end{array}$ & $\begin{array}{l}\text { Altitude } \\
\text { dependent a priori } \\
\text { standard deviation }\end{array}$ & $\begin{array}{c}\text { Minimum } \\
\text { a priori standard } \\
\text { deviation }\end{array}$ & $\begin{array}{l}\text { Uncertainty } \\
\text { of spectros- } \\
\text { copic data }\end{array}$ \\
\hline $\mathrm{C}_{2} \mathrm{H}_{6}$ & midlat./tropical ${ }^{1}$ & midlat./tropical ${ }^{1}$ & $5 \%$ & $10 \%$ \\
\hline $\mathrm{ClONO}_{2}$ & tropical $^{1}$ & tropical $^{1}$ & $5 \%$ & $3.5 \%$ \\
\hline $\mathrm{CO}_{2}$ & $\begin{array}{l}\text { modified } \\
\text { global }^{1}\end{array}$ & global $^{1}$ & $5 \%$ & $5 \%$ \\
\hline CFC-11 & $\begin{array}{l}\text { HAGAR, } \\
\text { midlat./tropical }^{1}\end{array}$ & $\begin{array}{l}\text { HAGAR, } \\
\text { midlat./tropical }^{1}\end{array}$ & $5 \%$ & $3 \%$ \\
\hline CFC-113 & $\begin{array}{l}\text { modified } \\
\text { global }^{1}\end{array}$ & - & $10 \%$ & $5 \%$ \\
\hline CFC-114 & global $^{1}$ & - & $5 \%$ & $5 \%$ \\
\hline CFC-12 & $\begin{array}{l}\text { HAGAR } \\
\text { midlat./tropical }\end{array}$ & $\begin{array}{l}\text { HAGAR, } \\
\text { midlat./tropical }^{1}\end{array}$ & $5 \%$ & $1 \%$ \\
\hline HCFC-22 & $\begin{array}{l}\text { ACE-FTS or } \\
\text { global }^{1}\end{array}$ & global $^{1}$ & $5 \%$ & $4 \%$ \\
\hline $\mathrm{HNO}_{4}$ & midlat./tropical ${ }^{1}$ & midlat./tropical ${ }^{1}$ & $5 \%$ & $10 \%$ \\
\hline OCS & global $^{1}$ & global $^{1}$ & $5 \%$ & $10 \%$ \\
\hline Pressure & ECMWF & - & $1 \%$ & - \\
\hline
\end{tabular}

${ }^{1}$ Remedios et al. (2007b)

CFC-11 was measured by the in situ instrument HAGAR on M55-Geophysica during the AMMA campaign. The profiles measured during ascent and descent of M55-Geophysica are combined with CFC-11 values above the flight altitude from the MIPAS reference atmosphere scaled to the measured values and smoothed at the transition. The CFC-11 a priori covariance is a combination of the climatological error and the difference between the HAGAR ascent and descent profiles.
The a priori standard deviation for the altitude retrieval is given as standard deviation of the pointing angle of $0.5^{\circ}$. No correlation length is set for the tangent altitudes. Atmospheric refraction has a significant effect for lower tangent altitudes and is included in the radiative transfer model.

In the retrieval process, the tangent heights of the observations are varied keeping all other atmospheric variables and parameters on a fixed vertical atmospheric grid, i.e. there 
Table 5. Radiance uncertainties.

\begin{tabular}{lccccc}
\hline ISB $\left[\mathrm{cm}^{-1}\right]$ & $\begin{array}{c}\text { Forward Model } \\
\text { standard deviation [\%] }\end{array}$ & $\begin{array}{c}\text { Offset } \\
{\left[\mathrm{W} / \mathrm{m}^{2} \mathrm{srcm}^{-1}\right]}\end{array}$ & $\begin{array}{c}\text { Gain } \\
{[\%]}\end{array}$ & $\begin{array}{c}\text { Absolute noise } \\
{\left[\mathrm{W} / \mathrm{m}^{2} \mathrm{sr} \mathrm{cm}^{-1}\right]}\end{array}$ & $\begin{array}{c}\text { Relative } \\
\text { noise [\%] }\end{array}$ \\
\hline $777.8-778.7$ & 0.70 & 0.0015 & 1 & 0.00005 & 1 \\
$784-785$ & 0.82 & 0.0015 & 1 & 0.00005 & 1 \\
$787-790$ & 0.51 & 0.0015 & 1 & 0.00005 & 1 \\
$791-793$ & 0.35 & 0.0015 & 1 & 0.00005 & 1 \\
$794.1-795$ & 0.45 & 0.0015 & 1 & 0.00005 & 1 \\
$796.6-797.5$ & 0.42 & 0.0015 & 1 & 0.00005 & 1 \\
$832-832.9$ & 0.25 & 0.0015 & 1 & 0.00005 & 1 \\
$844.3-847.3$ & 0.21 & 0.0015 & 1 & 0.00005 & 1 \\
$863-864$ & 0.18 & 0.0015 & 1 & 0.00005 & 1 \\
\hline
\end{tabular}

are two independent grids: one for the retrieved atmospheric quantities and one for the "instrument related" quantities like tangent altitude and offset. A similar concept was also used by Kiefer et al. (2007) for MIPAS observations.

\subsection{Averaging kernel, measurement contribution, and comparison with independent data}

For the interpretation of the retrieval results it is important to have measures indicating how a retrieved value depends one measurement information and a priori data. Such measures can be derived from the averaging kernel (AVK) matrix. The AVK matrix describes the sensitivity of the retrieval to the true state (Rodgers, 2000):

$\hat{\boldsymbol{x}}=\mathbf{A} \boldsymbol{x}+(\mathbf{I}-\mathbf{A}) \boldsymbol{x}_{\mathrm{a}}+\mathbf{G} \epsilon$,

where $\mathbf{A}$ is the AVK matrix, $\mathbf{I}$ the identity matrix, $\boldsymbol{x}_{\mathrm{a}}$ the a priori state, $\hat{\boldsymbol{x}}$ the retrieval result, $\boldsymbol{x}$ the true state and $\mathbf{G} \epsilon$ is the retrieval error. The gain matrix $\mathbf{G}$ maps from measurement space to state space. The retrieval resolution and the measurement contribution are derived from the AVK: Following Purser and Huang (1993) the resolution is determined as information density (reciprocal of the trace of the AVK matrix) multiplied by the vertical grid spacing. The measurement contribution is calculated as the sum over the rows of the AVK matrix. The measurement contribution is an approximate measure of the proportion to which measurement and a priori information contribute to the retrieval results (Rodgers, 2000). A value of 0.0 for the measurement contribution means, that the result contains only a priori information. A value of 1.0 means that the result contains only measurement information. However, the measurement contribution can exceed the value of one in case of non-linearities or due to large retrieval errors.

When the retrieved profiles are compared to independent profiles with higher vertical resolution the AVK matrix needs to be considered. The retrieval result can be regarded as a combination of the unknown real state, the a priori and the retrieval errors (Rodgers, 2000), see also Eq. (2). For comparison we use in situ data measured on-board M55Geophysica with a higher time and altitude resolution and relatively small errors. Assuming that the independent data have ideal characteristics they can be degraded with the AVK to be comparable to the CRISTA-NF retrieval result, following e.g. von Clarmann (2006):

$\boldsymbol{x}_{\mathrm{ind}(\mathrm{AVK})}=\mathbf{A} \boldsymbol{x}_{\text {ind }}+(\mathbf{I}-\mathbf{A}) \boldsymbol{x}_{\mathrm{a}}$

where $\boldsymbol{x}_{\text {ind }}$ are the independent data (transferred to the retrieval grid) and $\boldsymbol{x}_{\text {ind(AVK) }}$ are the resulting data. In order to not restrict the altitude range for comparison, the profile of in situ measurements is extended with the a priori value used for the CRISTA-NF retrieval above the flight altitude in Eq. (3). When comparing in situ profiles to CRISTA-NF data later on the original and the degraded in situ measurements are shown. For comparison along the flight path the in situ data are not degraded because no in situ measurements are available above and below the flight altitude and additional information would be necessary to apply Eq. (3). Alternatively, in situ data may be compared directly (i.e. without applying the AVK) to CRISTA-NF measurements if the smoothing errors of the retrieval are taken into account (see next section).

\subsection{Error analysis}

In this section, we discuss the error budget of the CRISTA$\mathrm{NF}$ observations based on typical profile data for $\mathrm{H}_{2} \mathrm{O}$ and $\mathrm{O}_{3}$ obtained during a tropical flight from Ouagadougou (Burkina Faso) on 13 August 2006. Figure 4 shows retrieved mixing ratio values of $\mathrm{H}_{2} \mathrm{O}$ and $\mathrm{O}_{3}$ for forward spectra and backward spectra (see Sect. 2) together with the corresponding a priori profiles. A priori water vapor volume mixing ratios are taken from the MIPAS reference atmospheres for tropical conditions (Remedios et al., 2007b). The a priori standard deviation was set to a maximum of $50 \%$ and 200 ppmv below $17 \mathrm{~km}$ altitude and $2 \mathrm{ppmv}$ constant above. This leads to a low error estimate above $17 \mathrm{~km}$ to reflect the lower stratospheric variability. Below a higher, conservative error estimate is used. The $\mathrm{H}_{2} \mathrm{O}$ mixing ratio is retrieved up to an 
a) $\mathrm{H}_{2} \mathrm{O}$

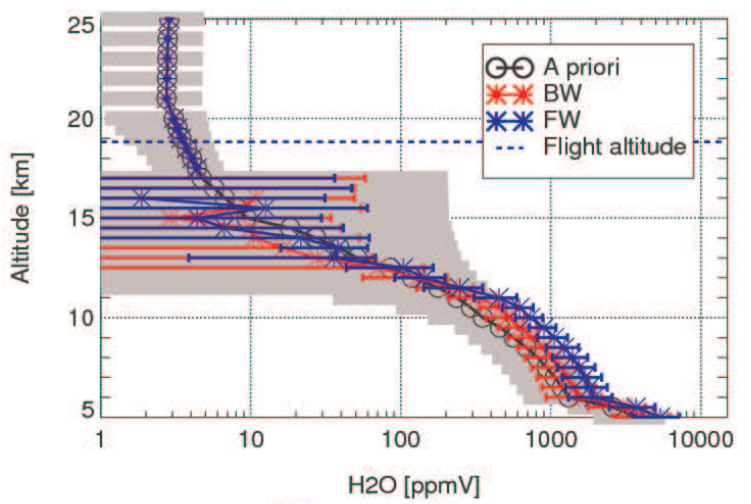

c)Temperature

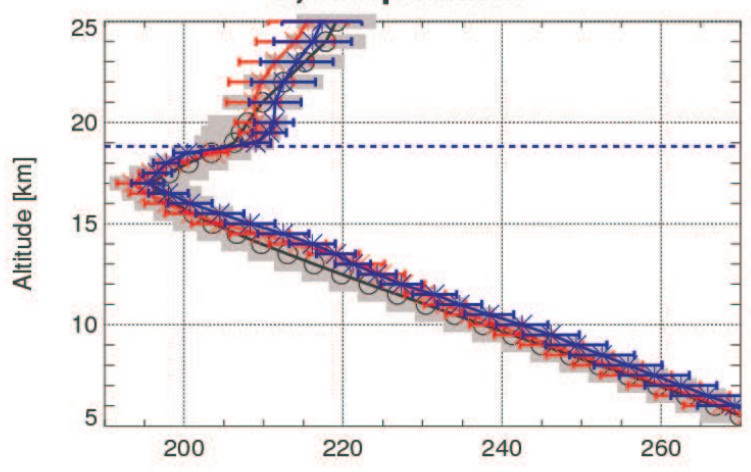

e) $\mathrm{HNO}_{3}$

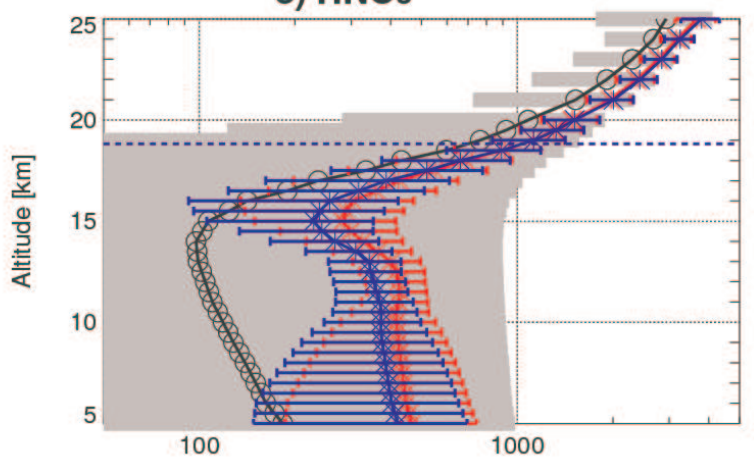

HNO3 [pptV]

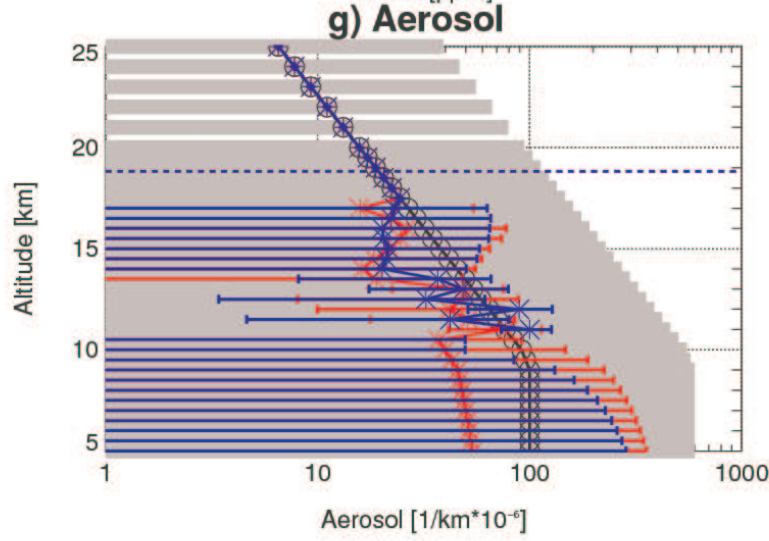

b) $\mathrm{O}_{3}$

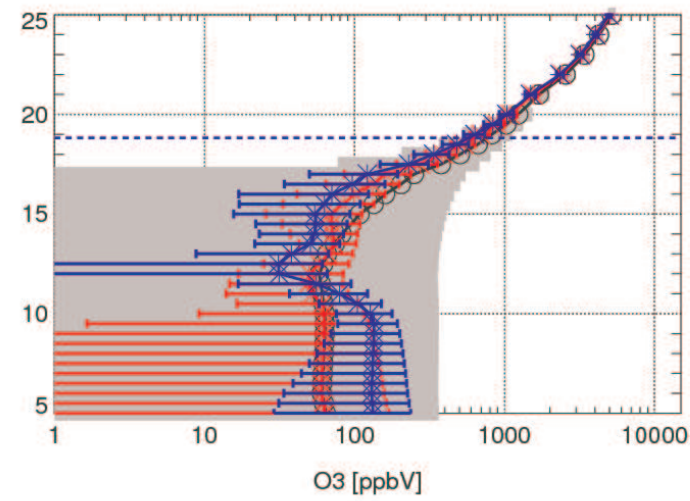

d) $\mathrm{CCl}_{4}$

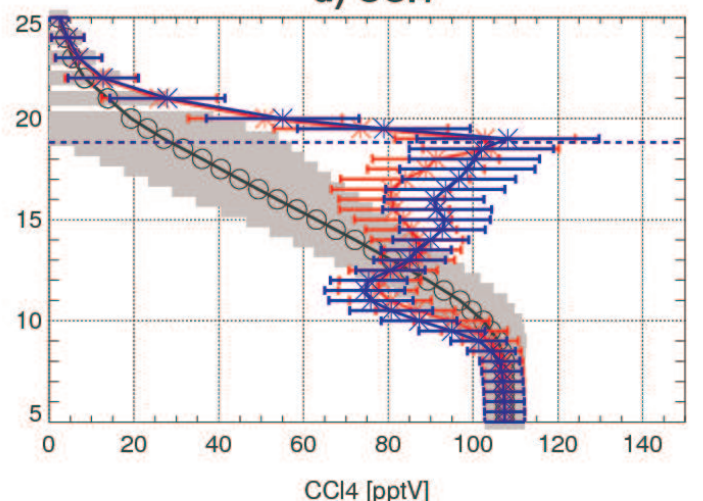

f) PAN

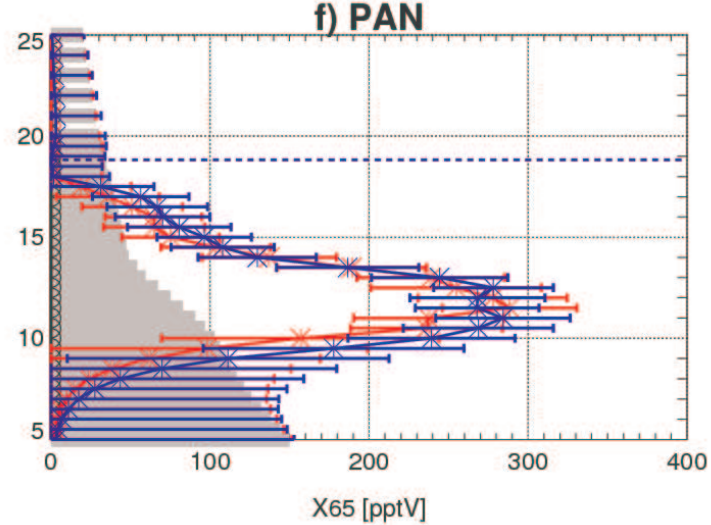

Fig. 4. Profiles for forward (FW) and backward (BW) spectra with combined plus smoothing error of $\mathrm{H}_{2} \mathrm{O}_{2} \mathrm{O}_{3}$, temperature, $\mathrm{CCL}_{4}, \mathrm{HNO}_{3}$, PAN, and aerosol extinction for profile 87, flight L5. The a priori standard deviation is shown in gray (y-axis vary). 
altitude of $17 \mathrm{~km}$. For the spectral range used in our retrieval approach $\left(\mathrm{H}_{2} \mathrm{O}\right.$ line at $\left.784 \mathrm{~cm}^{-1}\right)$, the detection limit for water vapor is about 10 to $15 \mathrm{ppmv}$ in this detector channel.

The retrieved $\mathrm{O}_{3}$ volume mixing ratios are compared with a priori data obtained from ECMWF (Fig. 4b). The a priori standard deviation for $\mathrm{O}_{3}$ is set to a maximum of 5\% or 300 ppbv. The small a priori standard deviation for $\mathrm{O}_{3}$ and $\mathrm{HNO}_{3}$ above $18 \mathrm{~km}$ reflects the presumably lower temporal and spatial variability in the stratosphere and is necessary to stabilize the retrieval. This leads also to small a posteriori errors for $\mathrm{O}_{3}$ and $\mathrm{HNO}_{3}$ above $18 \mathrm{~km}$. We cannot rule out the possibility that it leads to an underestimation of the $\mathrm{O}_{3}$ retrieval errors where the resolution is low. At tangent points between flight altitude and $12 \mathrm{~km}$, values retrieved from forward and backward spectra agree well and are somewhat lower than the a priori value. Below $12 \mathrm{~km}$, ozone values obtained from the forward and backward spectra are higher than the a priori values and start to differ from each other. This is due to a lack of measurements below (lowest tangent altitude $10.5 \mathrm{~km}$ for backward and $9.8 \mathrm{~km}$ for forward spectra) as well as the large a priori correlation length.

Figure $4 \mathrm{c}$ shows the result of the temperature retrieval for forward and backward spectra. The retrieved temperatures are higher than the a priori temperature at about 11 to $15 \mathrm{~km}$ altitude. The result of the $\mathrm{CCl}_{4}$ retrieval for profile 87 is displayed in Fig. 4d. Large differences are found between the a priori profile from the Remedios climatology and the retrieval result. This most probably results from the fact, that there is only a global averaged profile in the climatology but the measurement take place in the tropic, i.e. the climatological profile is representative for an atmosphere with a much lower tropopause height. Figure $4 \mathrm{e}$ shows the result of the $\mathrm{HNO}_{3}$ retrieval for profile 87. The retrieval result shows a higher $\mathrm{HNO}_{3}$ abundance than the climatology. The retrieval result for PAN is shown in Fig. 4f. A zero profile is used as a priori while the a priori error is estimated from Glatthor et al. (2007). PAN volume mixing ratios up to about $280 \mathrm{pptv}$ are found between 10 and $15 \mathrm{~km}$ altitude. In Fig. $4 \mathrm{~g}$ the retrieval result for aerosol extinction is shown together with the a priori profile.

The errors of the retrieval results are shown in Fig. 4. The corresponding detailed error analysis is shown in Fig. 5. The error budget consists of several components including instrument and forward model errors:

- Smoothing error:

The smoothing error depends on the a priori covariance and the AVK matrix. However, in this study the a priori covariance does not represent a real ensemble of atmospheric states. Rather conservative estimates of the standard deviations are used in order to avoid a suppression of information obtained from the observation. This will cause some overestimation of the smoothing error. On the other hand, an error budget without smoothing error tends to underestimate the full error. When comparing the retrieval results to an estimate of the real state (e.g. high resolution in situ observations) the smoothing error should be included, when comparing to an estimate after degrading the data with the AVK it should be omitted.

- Forward model error:

The forward model error is determined by comparing the fast forward model remaining after regression correction with the line-by-line model reference model output. The forward model error is a function of tangent height and ISW and varies between about 0.2 and $0.8 \%$.

- Uncertainties of spectroscopic data:

The errors caused by uncertainties of the spectral line data and tabulated asorption cross-sections from HITRAN 2004.

- Model parameter errors:

Retrieval errors caused by the uncertainties of the forward model parameters, i.e. interfering species, reference pressure, and top column data of retrieval variables. In Fig. 5 this error is divided into contributions from temperature column and reference pressure as well as the one from interfering species.

- Instrument error:

The instrument error comprises the radiometric offset and gain uncertainties. These uncertainties are estimated in the frame of the black body calibration (for details see Schroeder et al., 2009). A radiometric offset of about $0.0015 \mathrm{~W} /\left(\mathrm{m}^{2} \mathrm{sr} \mathrm{cm}^{-1}\right)$ was determined for detector LRS6 during calibrations. The gain error is on the order of $1 \%$.

- Noise:

This is the error caused by measurement noise. For detector LRS6, it is estimated to $0.00005 \mathrm{~W} /\left(\mathrm{m}^{2} \mathrm{sr} \mathrm{cm}^{-1}\right)$. However, in our retrieval setup a value of $1 \%$ is used to compensate for any missing retrieval error and to achieve agreement in the forward model fits (see discussion below).

The combined error shown in Fig. 5 is the square root of the sum of all components mentioned above except for the smoothing error. The leading terms of the combined error for most of the retrieved variables are the errors due to the non-retrieved emitters, the spectral line data and the noise. The instrumental errors, forward model errors and pressure and temperature uncertainties play a minor role. The error components vary somewhat between different profiles but the profile shown in Fig. 5 can be considered to be representative. Other possible error sources are effects of an insufficient representation of aerosol extinction, thin clouds, the horizontal structure along the LOS, remaining effects of detector relaxations or of the determination of the spectral resolving power, undetected stray light and spikes, and uncertainties in 
a) $\mathrm{H}_{2} \mathrm{O}$

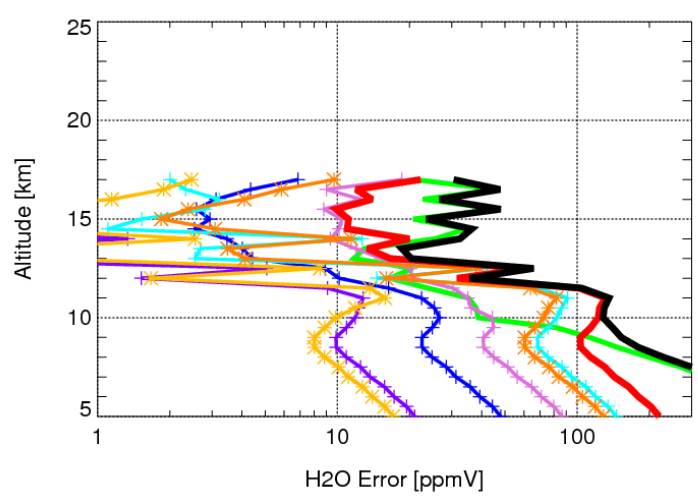

c)Temperature

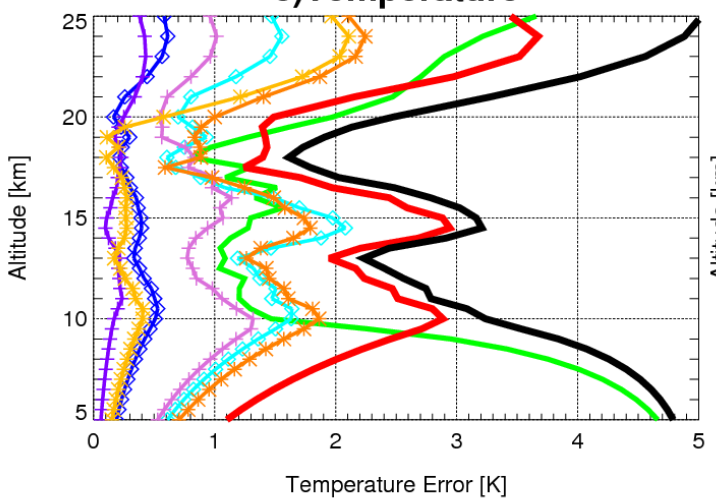

e) $\mathrm{HNO}_{3}$

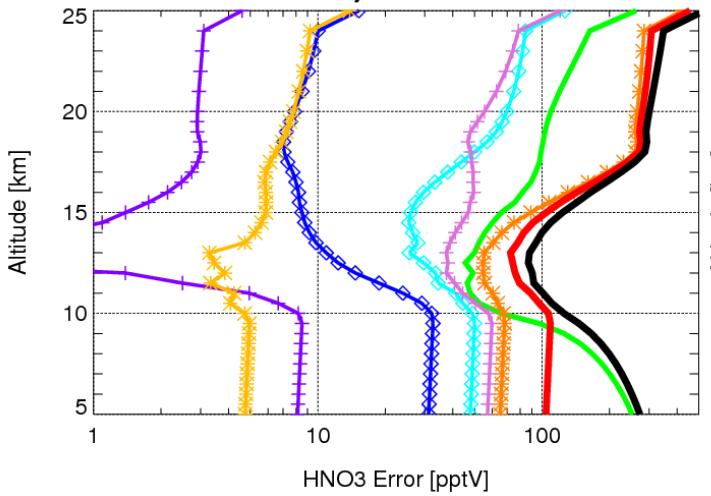

g) Aerosol

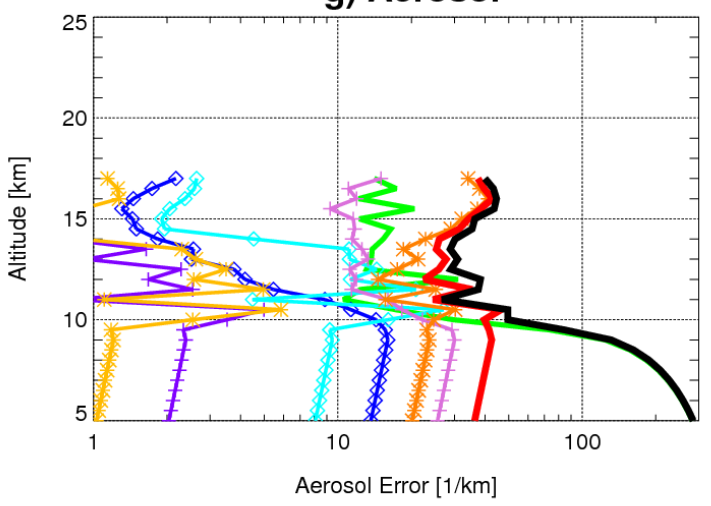

b) $\mathrm{O}_{3}$
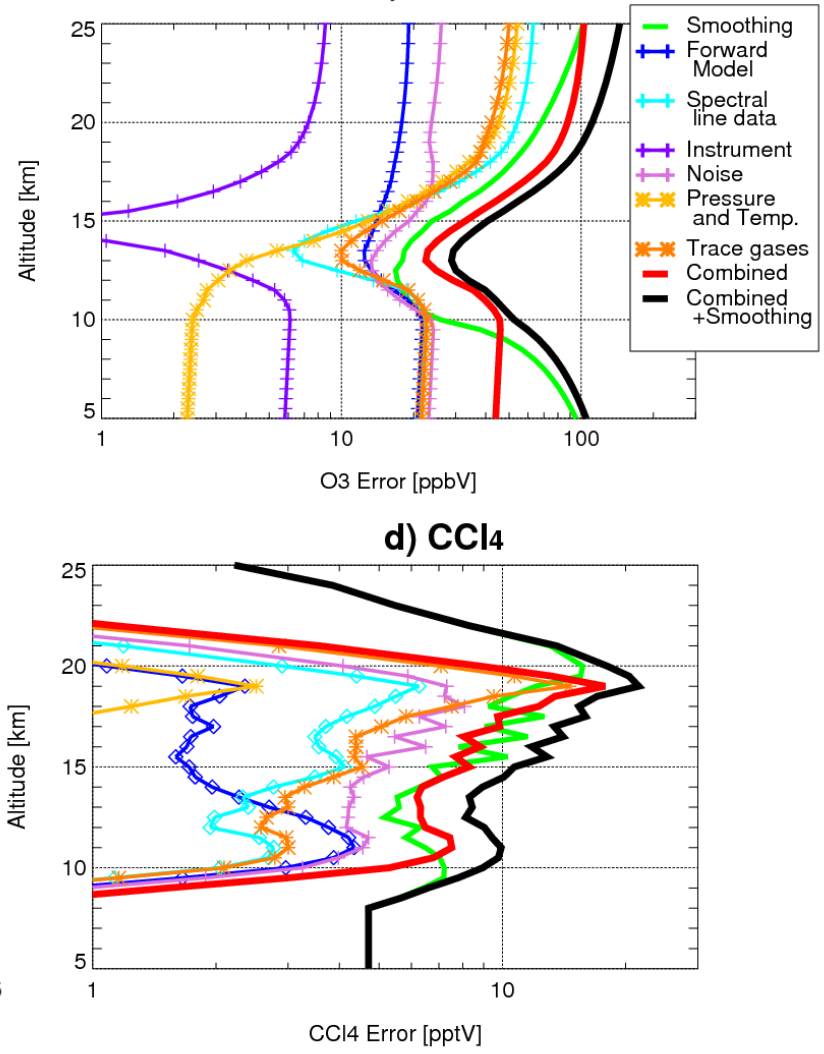

f) PAN

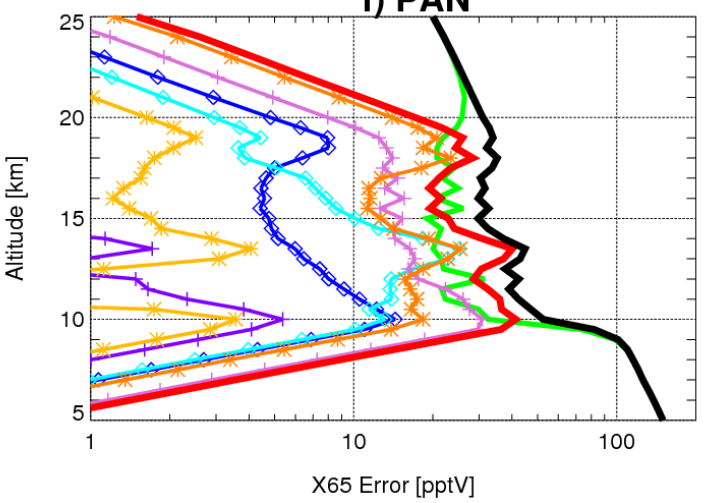

Fig. 5. Error components for $\mathrm{H}_{2} \mathrm{O}, \mathrm{O}_{3}$, temperature, $\mathrm{CCL}_{4}, \mathrm{HNO}_{3}$, PAN, and aerosol extinction for profile 87 (forward spectra), flight $\mathrm{L} 5$ (y-axis vary). 
the line-by-line reference model. It is therefore important to check the error budget by comparison of the retrieval results to independent data.

The vertical resolution and measurement contribution of the observations are used to identify and filter for low-quality data. Figure 6a shows the AVKs, vertical resolution and measurement contribution for $\mathrm{H}_{2} \mathrm{O}$. The resolution reaches often values better than $1 \mathrm{~km}$ and can be $500 \mathrm{~m}$ in the ideal case. Fluctuations in the resolution are mainly cause by a varying altitude sampling due to roll movements of the aircraft. The measurement contribution is close to 1.0 from the lowest tangent altitude up to $17 \mathrm{~km}$. This is used as additional indicator for the vertical range where the $\mathrm{H}_{2} \mathrm{O}$ retrievals are reliable (e.g. Hoffmann et al., 2008). Figure $6 \mathrm{~b}$ shows the AVKs, vertical resolution and measurement contribution for $\mathrm{O}_{3}$. The AVK peaks are broader here and rarely reach maximum values higher than 0.3 . The AVKs, vertical resolution and measurement contribution for temperature, $\mathrm{CCl}_{4}, \mathrm{HNO}_{3}$, PAN and aerosol extinction are shown in Fig. 6c-g. The upper threshold for the resolution is set to $20 \mathrm{~km}$ for $\mathrm{HNO}_{3}$ and $\mathrm{O}_{3}$ and $3 \mathrm{~km}$ for all other retrieval variables; the lower and upper thresholds for the measurement contribution are 0.8 and 1.2, respectively. In the following, only retrieval results meeting these quality criteria are displayed. The vertical resolution for all profiles from Flight L5 for the retrieved trace gases and temperature can be found in the electronic supplement.

The retrievals generally reproduce measured radiance within the specified error bars (see for example Fig. 2). The consistency of these retrieval results with the measurements and a priori data can be validated by a $\chi^{2}$-test (e.g. Rodgers, 2000). As for the CRISTA-NF $\mathrm{H}_{2} \mathrm{O}$ retrieval for SCOUT-O3 (Hoffmann et al., 2009), most values of the normalized $\chi^{2}$ for the retrieval result are smaller or close to 1.0 indicating that the retrievals are consistent with the measured and a priori data within their error estimates. Outliers with a normalized $\chi^{2}$ larger than two are excluded from further analyzes.

\section{Results}

\subsection{Temperature results}

Figure 7 shows the result of the temperature retrieval for flight L5 as a function of height and measurement time (horizontal location). Temperature data are presented as colored symbols. During the whole flight the lowest temperatures are found at altitudes of 17 to $18 \mathrm{~km}$. Spectra with a cloud index smaller than 3.5 are represented by black dots. Gaps in this 2-D representation of the temperature field (blank areas) are caused by the exclusion of data violating our quality criteria (see Sect. 4). For comparison with the CRISTA-NF temperatures, we included in situ temperature measurements by the Thermo Dynamic Complex (TDC; Shur et al., 2007) from the Central Aerological Observatory (CAO) in Moscow.
The data of this instrument are plotted between the two solid black lines indicating the flight altitude of the aircraft.

The M55-Geophysica started in Ouagadougou and flew southwards, climbing up to nearly $19 \mathrm{~km}$ and then performing a so-called "dive" by descending down to about $13 \mathrm{~km}$. After climbing again to a flight altitude of about $19 \mathrm{~km}$, the aircraft turned around, flew northward, climbed above $20 \mathrm{~km}$ before it started the final descent and landing in Ouagadougou. CRISTA-NF looks to the starboard side of the aircraft, thus westward during the first half of the flight and eastward during the second half (see Fig. 3 for the flight path). With the exception of a few profiles, clouds or optical dense conditions are only found below 8 to $13.5 \mathrm{~km}$.

The in situ temperatures agree in most cases well with the CRISTA-NF measurements made in the vicinity of the aircraft (see Fig. 7). In addition, we compare in situ profiles measured during the ascend and descend of the aircraft to all limb-profiles obtained during the flight (Fig. 8). For this comparison, it should be kept in mind that the tangent points of the observation move away from the instrument with decreasing altitude and reach a distance of about $200 \mathrm{~km}$ for a tangent height of $10 \mathrm{~km}$ at highest flight levels.

The mean in situ temperature profile shown in Fig. 7 is folded with the mean AVKs of all CRISTA-NF profiles, since each profile resulting from the CRISTA-NF retrieval has a somewhat different AVK matrix. The resulting in situ temperature profiles agree well with the original in situ measurements, indicating a relatively small influence of the CRISTANF AVKs on the results. Above 15 and below $11 \mathrm{~km}$ the mean CRISTA-NF temperature profile agrees with the mean in situ temperatures within the combined error. Between 11 and $15 \mathrm{~km}$ the CRISTA-NF data are systematically higher than the in situ data (up to $5 \mathrm{~K}$ ). This may be partly caused by uncertainties in the altitude determination since similar deviations are also found most other flights (see Weigel, 2009). If temperature and altitude retrieval are not completely independent this can also influence the retrieval results for the trace gases, especially when they vary strongly with altitude.

CRISTA-NF temperature observations in the vicinity of the aircraft and corresponding and in situ measurements agree rather well in term of relative variations along the horizontal flight track. This is demonstrated in Fig. 8b that shows the in situ temperature data in comparison with the CRISTA-NF results at retrieval grid altitudes just below and above the flight track. In addition, ECMWF temperatures are shown that are interpolated onto the same positions. In most cases, the values of the situ measurements are between the corresponding CRISTA-NF temperatures (located below and above). In addition, CRISTA-NF measurements resemble much more of the horizontal variations found in the in situ temperatures than in corresponding ECMWF data. 

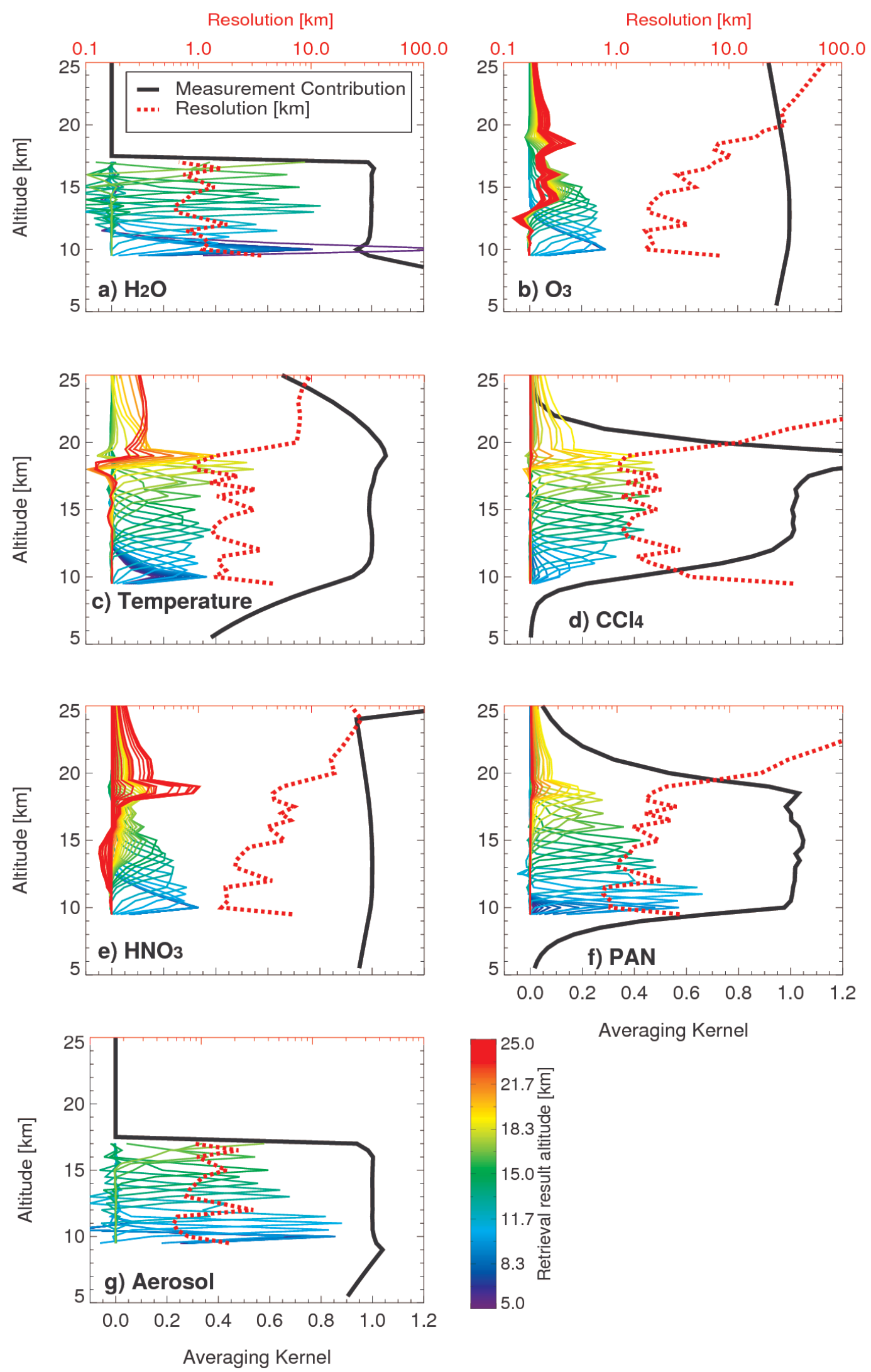

Fig. 6. Averaging kernel matrix, measurement contribution and resolution for $\mathrm{H}_{2} \mathrm{O}, \mathrm{O}_{3}$, temperature, $\mathrm{CCL}_{4}, \mathrm{HNO}_{3}$, $\mathrm{PAN}_{\text {, and aerosol }}$ extinction for profile 87 (forward spectra), flight L5. 


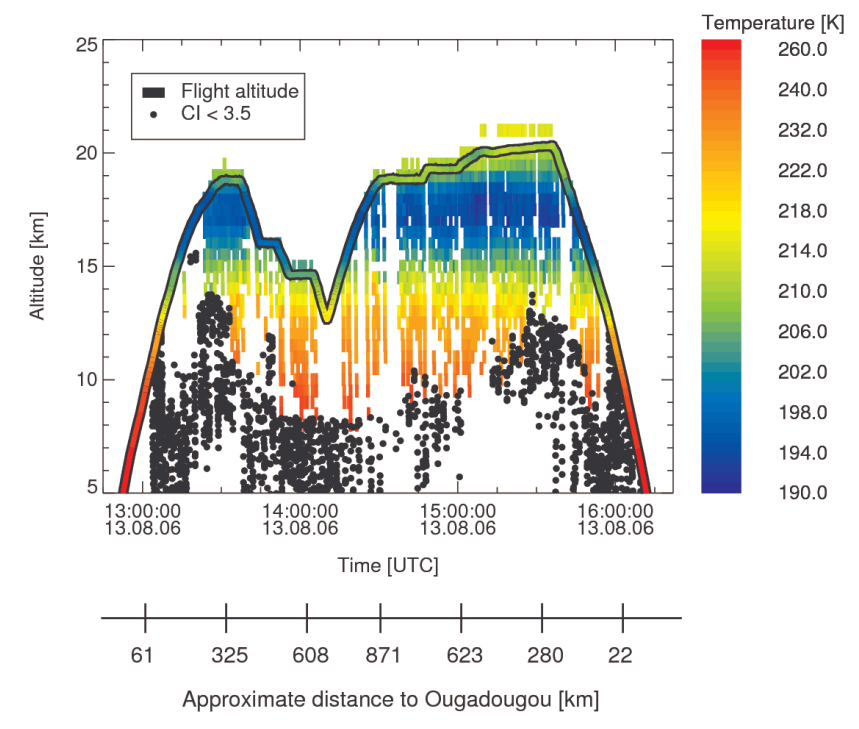

Fig. 7. CRISTA-NF and TDC temperatures during flight L5. The TDC temperatures are plotted along the flight altitude with the same color scale as the 2-D representation of CRISTA-NF temperatures. Black dots mark spectra with a CI lower than 3.5. Note the nonlinear color scale.

\subsection{Trace gas results}

Figure 9 shows the results of the $\mathrm{H}_{2} \mathrm{O}$ retrieval along the flight track together with total water measured in situ by the Fast In situ Stratospheric Hygrometer (FISH; Zoeger et al., 1999). Since CRISTA-NF observes gas-phase water and FISH measures total water (including water droplets and ice crystals), only FISH measurements for non saturated conditions are included in the comparison. For water vapor, individual CRISTA-NF profiles with good signal to noise ratio are available up to $15 \mathrm{~km}$ altitude. Therefore only FISH measurements obtained during the ascent, dive and descent of the aircraft (below $15 \mathrm{~km}$ ) can be compared.

CRISTA-NF $\mathrm{H}_{2} \mathrm{O}$ mixing ratios are generally higher than FISH measurements obtained during ascend, dive, and descend (below $15 \mathrm{~km}$ ). This also applies to $\mathrm{H}_{2} \mathrm{O}$ profiles obtained from the flight path segments with nearly constant altitudes. However, all of these measurements have a considerable horizontal distance to the closest CRISTA-NF profiles, which makes comparisons difficult as a result of the enormous variability of water vapor in the troposphere. Unfortunately, there are no CRISTA-NF profiles even close to these ascent in situ data (Fig. 9). In particular, during the ascent of the aircraft, FISH $\mathrm{H}_{2} \mathrm{O}$ mixing ratios are much lower. Interestingly, the best agreement is obtained for the last limbprofile before descent, which has the smallest horizontal distance to the corresponding in situ measurement location (see Fig. 10b). It seems therefore likely that the higher $\mathrm{H}_{2} \mathrm{O}$ mixing ratios from CRISTA-NF are at least partly due to higher $\mathrm{H}_{2} \mathrm{O}$ mixing ratios south of Ouagadougou. Further evidence
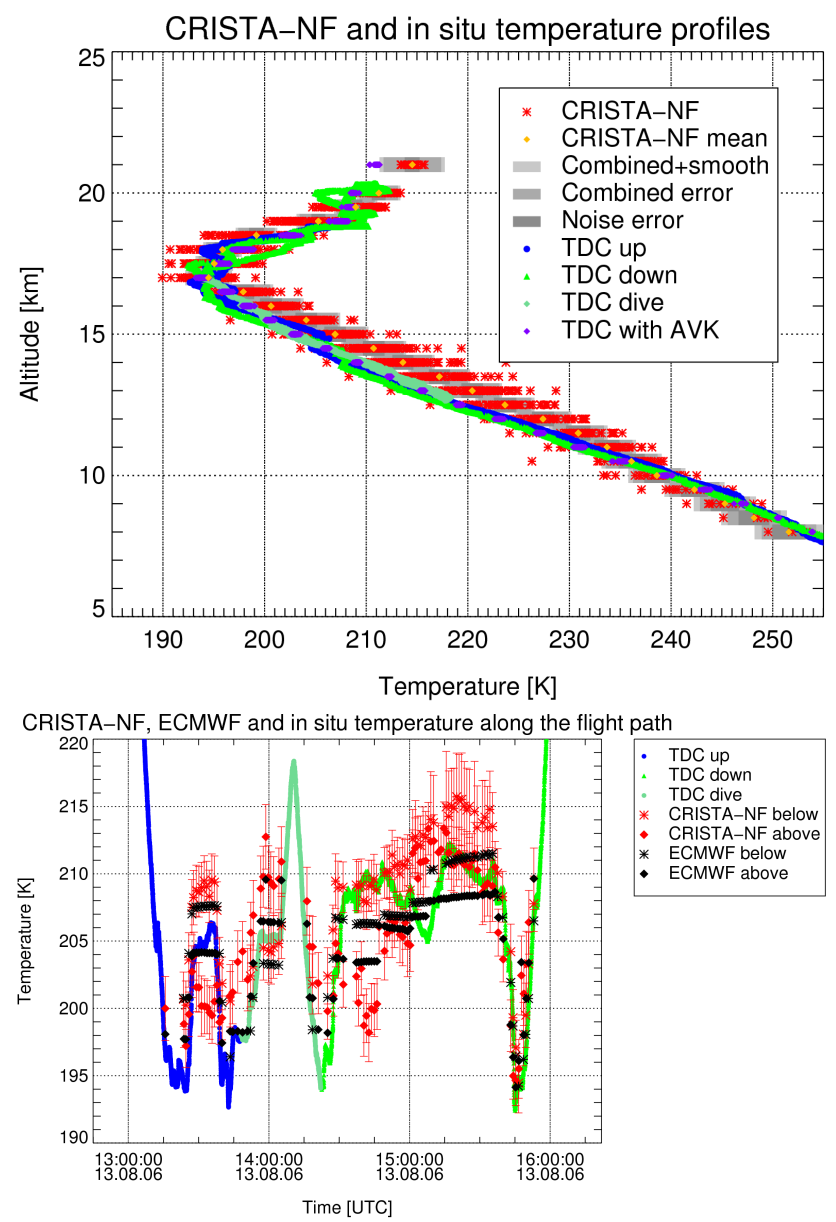

Fig. 8. CRISTA-NF and TDC temperatures during flight L5 shown as profiles (a) and along the flight path (b). Along the flight the CRISTA-NF temperature from the retrieval grid point below and above the flight path are shown. Error bars on CRISTA-NF data indicate combined plus smoothing error.

for this is the fact that CRISTA-NF $\mathrm{H}_{2} \mathrm{O}$ observations agree much better to respective values from in situ observations for several other flights, e.g. on 29 July 2006 (Fig. 11). The large spatial and temporal variation of $\mathrm{H}_{2} \mathrm{O}$ for flight $\mathrm{L} 5$ from Ouagadougou is also reflected by large differences observed by FISH during ascent (lower values) and descent (higher values).

Figure 12 shows a cross section of the CRISTA-NF $\mathrm{O}_{3}$ retrieval results for the same flight. In general, the $\mathrm{O}_{3}$ volume mixing ratios are lower than about $200 \mathrm{ppbv}$ below $17 \mathrm{~km}$ and increase rapidly above this level. There are several profiles with relatively high $\mathrm{O}_{3}$ volume mixing ratios between 100 and $200 \mathrm{ppbv}$ below $15 \mathrm{~km}$. Comparisons to ozone values measured by the Fast OZone ANalyzer (FOZAN; Yushkov et al., 1999) show good agreement (see also Fig. 13). Mean CRISTA-NF $\mathrm{O}_{3}$ values agree well with respective FOZAN measurements between 10 and $13.5 \mathrm{~km}$. The mean CRISTA-NF $\mathrm{O}_{3}$ values are lower above 


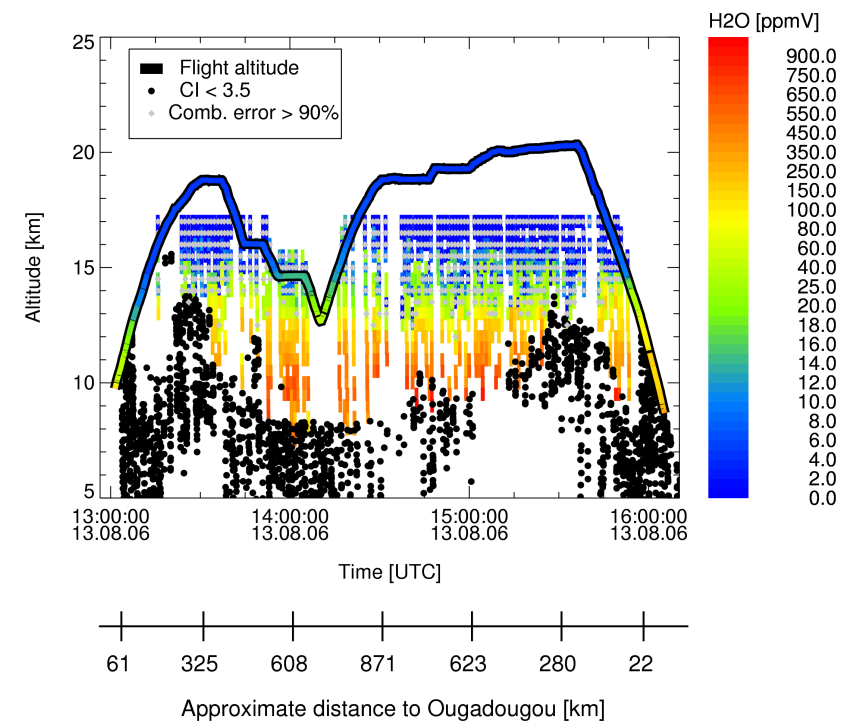

Fig. 9. CRISTA-NF and FISH $\mathrm{H}_{2} \mathrm{O}$ during flight L5. The FISH $\mathrm{H}_{2} \mathrm{O}$ are plotted along the flight altitude with the same color scale as the 2-D representation of CRISTA-NF $\mathrm{H}_{2} \mathrm{O}$. Black dots mark spectra with a CI lower than 3.5. Note the non-linear color scale.

this altitude range and higher at lower altitudes. However, for most cases the differences are within the combined error of the CRISTA-NF retrievals. Although the resolution of CRISTA-NF $\mathrm{O}_{3}$ observations is lower than for temperature and $\mathrm{H}_{2} \mathrm{O}$, the degradation of the FOZAN data with the AVKs has no large effect on the resulting in situ profile used for the comparison. For the other flights where FOZAN data are available (T3, T4) the CRISTA-NF $\mathrm{O}_{3}$ is systematically higher than the FOZAN measurements where the ozone mixing ratio becomes rather low, i.e. below 10 to $12 \mathrm{~km}$, respectively. The deviations from FOZAN exceed the CRISTANF covariance and smoothing error in these cases (Weigel, 2009).

CRISTA-NF and in situ data both show large horizontal variability of $\mathrm{O}_{3}$ along the flight track. CRISTA-NF $\mathrm{O}_{3}$ observations in the vicinity of the aircraft and corresponding and FOZAN in situ measurements agree rather well in term of relative variations along the horizontal flight track. This is demonstrated in Fig. 13b that shows the in situ ozone data in comparison with the CRISTA-NF results at retrieval grid altitudes just below and above the flight track. Note that even for the small vertical distance of $500 \mathrm{~m}$ significant differences of ozone mixing ratios are found in the CRISTA-NF observation, as a result of relatively steep vertical gradients. The $\mathrm{O}_{3}$ measurements of FOZAN are in between the higher CRISTA-NF $\mathrm{O}_{3}$ values at the retrieval grid points above and lower $\mathrm{O}_{3}$ values at the retrieval grid just below, but closer to the higher values. It should be noted that like in the case of temperature, the horizontal variability seen in the in situ data is better resembled by CRISTA-NF observations than by corresponding $\mathrm{ECMWF} \mathrm{O}_{3}$ fields.
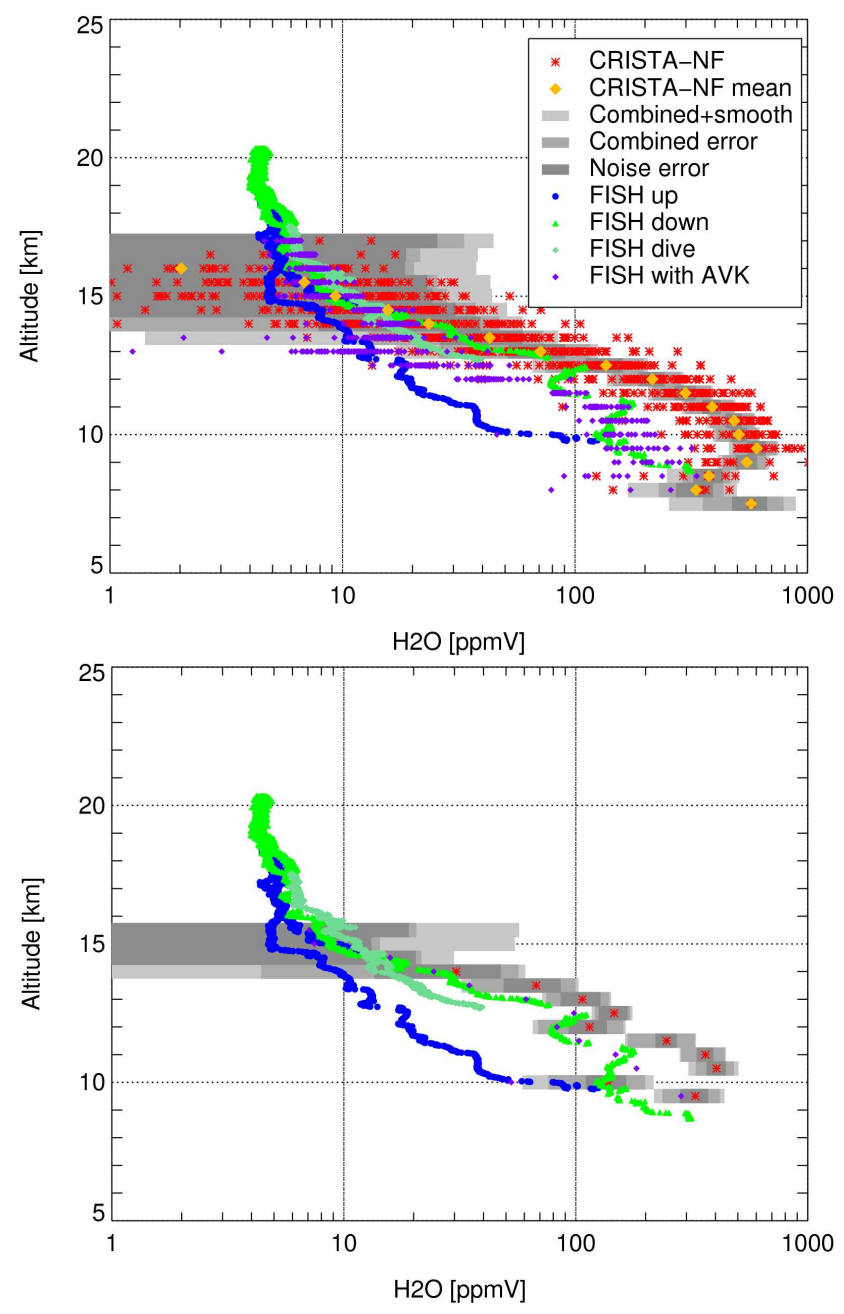

Fig. 10. CRISTA-NF and FISH $\mathrm{H}_{2} \mathrm{O}$ during flight $\mathrm{L} 5$ shown for all profiles (a) and profile 155 .

Retrieval results for $\mathrm{HNO}_{3}$, PAN, $\mathrm{CCL}_{4}$, and aerosol extinction are presented in Fig. 14. Again, strict filtering criteria are applied to CRISTA-NF data to show only reliable results. The most interesting feature of Fig. 14 is an enhancement of the amounts of $\mathrm{HNO}_{3}$ and PAN below $15 \mathrm{~km}$ altitude that might be caused by pollution sources of denser populated areas at Ouagadougou or areas at the coast of Côte d'Ivoire, Ghana, and Togo. Highest $\mathrm{HNO}_{3}$ mixing ratios associated with this pattern are found in the southern part of the flight and close to the descent in Ouagadougou below about $12 \mathrm{~km}$. With the exception of these polluted air masses, the mixing ratio of $\mathrm{HNO}_{3}$ monotonically increases with altitude. PAN mixing ratios rapidly decrease in the upper troposphere (above $14 \mathrm{~km}$ ) and reach values below the detection limit of CRISTA-NF at about $17 \mathrm{~km}$ altitude. The lowest $\mathrm{CCL}_{4}$ mixing ratios are found above the flight altitude at 20 to $21 \mathrm{~km}$, caused by the decrease of $\mathrm{CCL}_{4}$ in the stratosphere due to photolytic decomposition. 


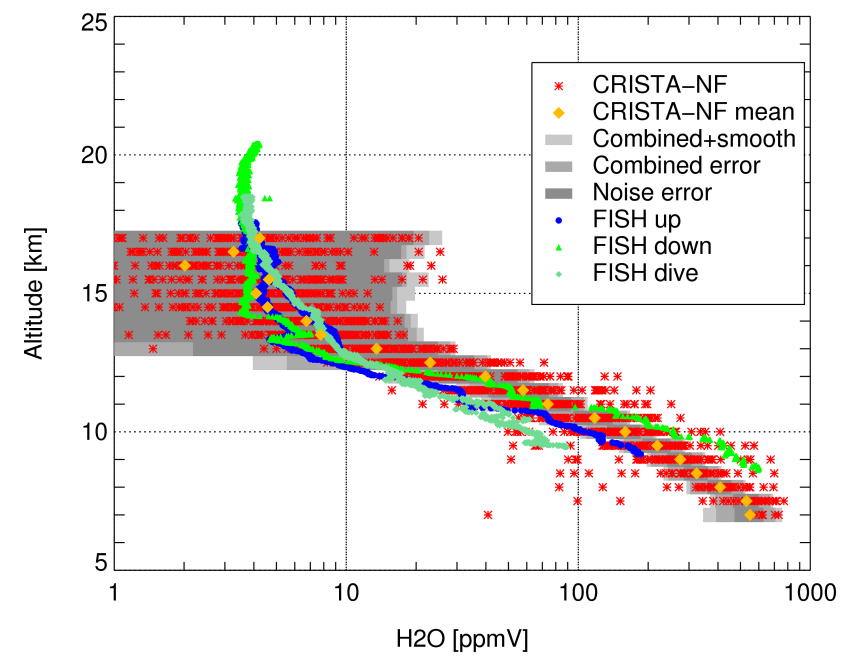

Fig. 11. CRISTA-NF and FISH $\mathrm{H}_{2} \mathrm{O}$ during flight TF2 shown for all profiles.

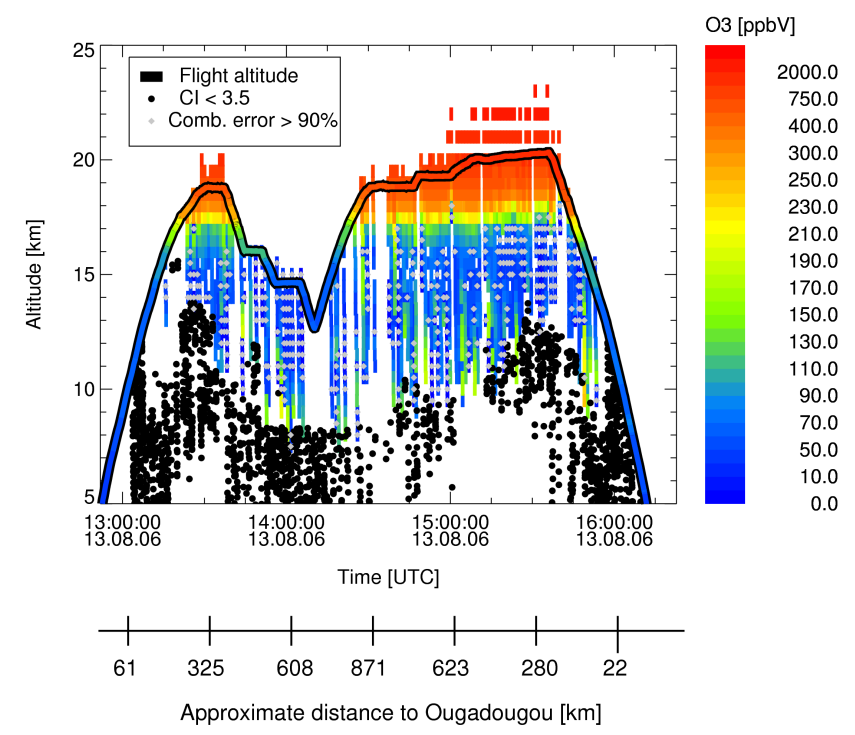

Fig. 12. CRISTA-NF and FOZAN $\mathrm{O}_{3}$ during flight L5. The FOZAN $\mathrm{O}_{3}$ are plotted along the flight altitude with the same color scale as the 2-D representation of CRISTA-NF O 3 . Black dots mark spectra with a CI lower than 3.5. Note nonlinear color scale.

\section{Discussion and summary}

In this paper, we present measurements by the CRISTA-NF instrument on-board the high-flying Russian research aircraft M55-Geophysica. The limb-sounding instrument provides profile observations with dense sampling in the vertical direction and horizontally along the flight track. With its capabilities it serves as a demonstrator for proposed UTLS satellite missions such as PRocesses Exploration through Measurements of Infrared and millimeter-wave Emitted Radiation (PREMIER) (e.g. Riese et al., 2005 and ESA, 2008).
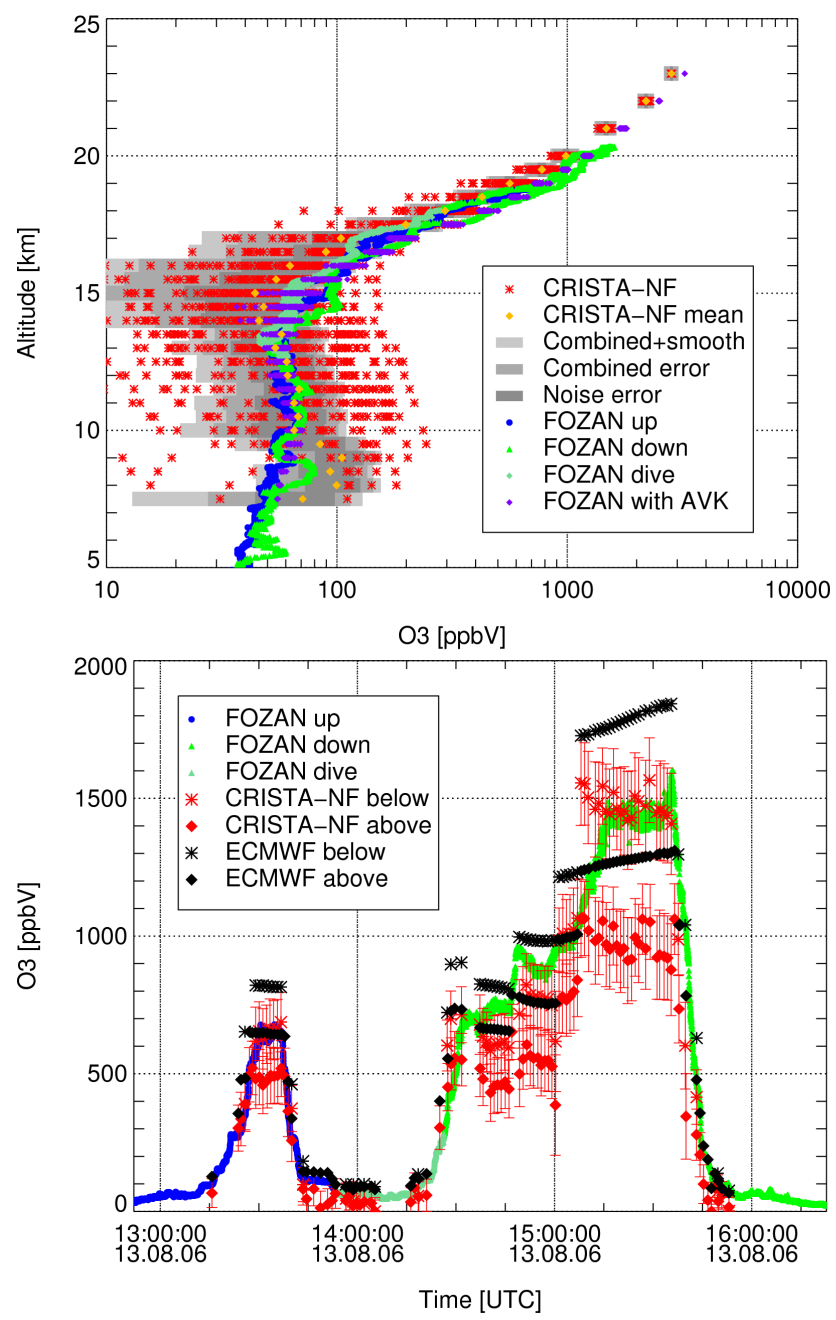

Fig. 13. CRISTA-NF and FOZAN $\mathrm{O}_{3}$ during flight L5 shown as profiles (a) and along the flight path (b). Along the flight the CRISTA-NF $\mathrm{O}_{3}$ from the retrieval grid point below and above the flight path are shown if both fulfill the quality requirements together with the combined plus smoothing error.

We utilized a fast radiative transfer model and retrieval processor to retrieve atmospheric data from nine spectral windows of an CRISTA-NF detector channel covering the spectral region from 776 to $868 \mathrm{~cm}^{-1}$. A new retrieval scheme is presented that provides atmospheric fields of temperature, $\mathrm{H}_{2} \mathrm{O}, \mathrm{O}_{3}, \mathrm{HNO}_{3}$, $\mathrm{PAN}, \mathrm{CCL}_{4}$, and aerosol extinction. At the same time, the radiometric offset and measurement altitudes are retrieved. Simultaneous retrieval of temperature and altitude are necessary due the insufficient accuracy of the combined M55-Geophysica and CRISTANF pointing system. Our approach involves a combination of limb-radiances from spectral bands around $792 \mathrm{~cm}^{-1}$ and $845 \mathrm{~cm}^{-1}$, in combination with good a priori knowledge of $\mathrm{CO}_{2}$ and CFC-11 mixing ratios. Within the altitude range covered by measurements the achieved vertical 

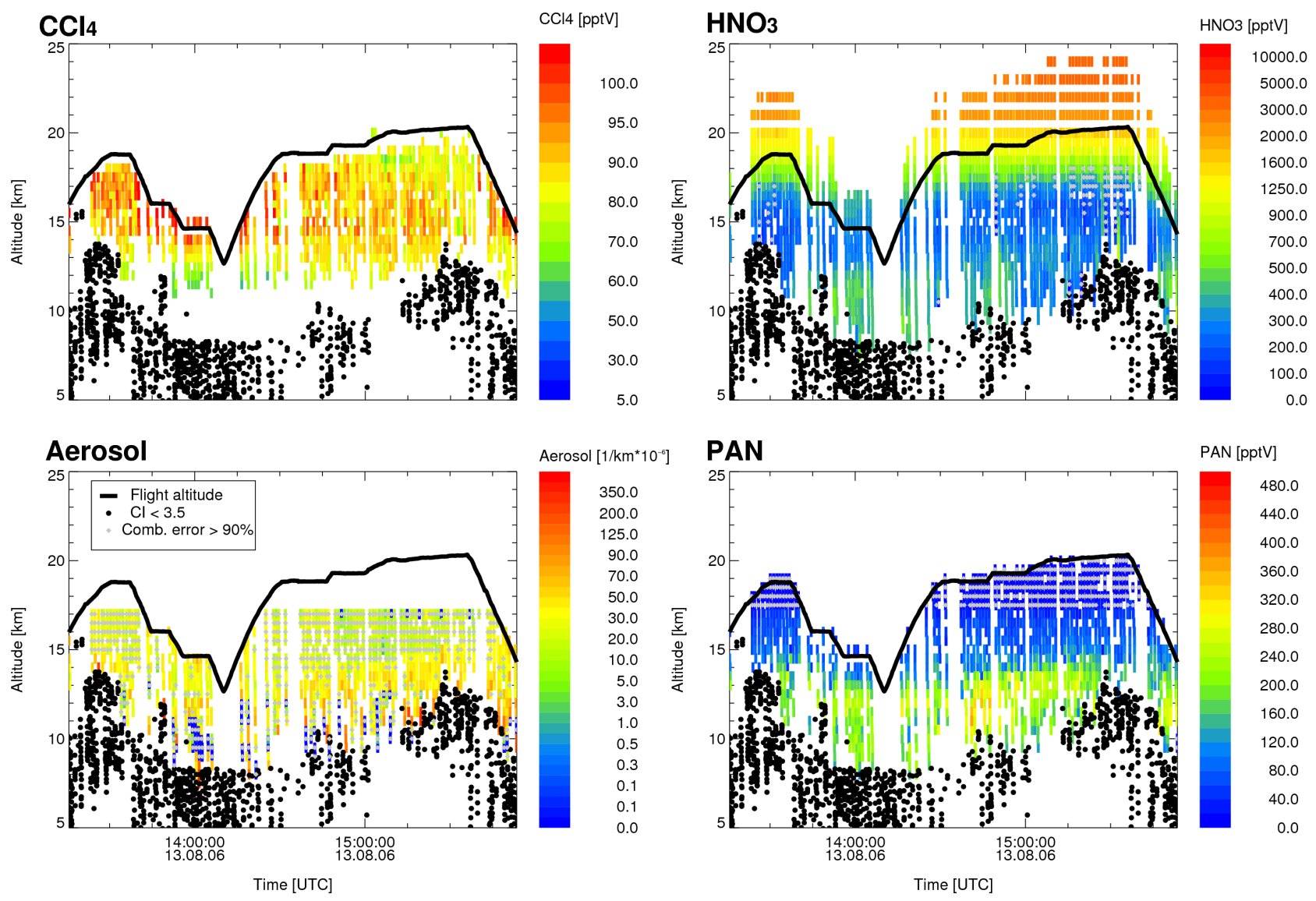

Fig. 14. CRISTA-NF results for $\mathrm{CCL}_{4}, \mathrm{HNO}_{3}$, aerosol extinction and PAN. Black dots mark spectra with a CI lower than 3.5. Note nonlinear color scales.

resolution of the retrieved atmospheric constituents varies between about $500 \mathrm{~m}$ and $3 \mathrm{~km}$, depending on the retrieved quantities and the tangent altitude sampling of the individual profiles. Measurement contribution and retrieval errors indicate a good data quality for $\mathrm{H}_{2} \mathrm{O}$ (below about $15 \mathrm{~km}$ ), temperature, $\mathrm{CCL}_{4}, \mathrm{PAN}, \mathrm{O}_{3}$, and $\mathrm{HNO}_{3}$. The distribution of the simultaneous retrieved trace gases and temperatures show an overall consistent result.

Retrieved profiles of CRISTA-NF temperature, $\mathrm{H}_{2} \mathrm{O}$, and $\mathrm{O}_{3} \mathrm{O}_{3}$ were compared to corresponding in situ observations on-board M55-Geophysica from TDC, FISH, and FOZAN. In general, the CRISTA-NF data agree well with in situ observations. Differences found can partly be explained by spatial differences between the measurement positions of CRISTA-NF and the in situ instruments. Some systematic differences between CRISTA-NF retrieval results and the in situ measurements were found, i.e. higher temperatures and $\mathrm{H}_{2} \mathrm{O}$ volume mixing ratios in the troposphere and low $\mathrm{O}_{3}$ volume mixing ratios in the lower stratosphere. Good agreement is found for temperature and $\mathrm{O}_{3}$ measurement in the vicinity of the aircraft, where is best spatial and temporal coincidence is obtained. For most cases, the absolute values of the CRISTA-NF observations are in good agreement with corresponding values from the the in situ measurements. In addition, CRISTA-NF measurements resemble the horizontal variations found in the in situ data better than corresponding ECMWF data.

\section{Supplementary material related to this article is available online at: http://www.atmos-meas-tech.net/3/1437/2010/ amt-3-1437-2010-supplement.pdf.}

Acknowledgements. The AMMA-SCOUT-O3 measurement campaign was facilitated by the European Commission and the EC Integrated Project SCOUT-O3 (505390-GOCE-CT-2004) and AMMA. Based on a French initiative, AMMA was built by an international scientific group and is currently funded by a large number of agencies. It has been the beneficiary of a major financial contribution from the European Communities Sixth Framework Research Program. Many thanks also to the team and pilots of the Myasishchev Design Bureau for making the M55-Geophysica flights possible under difficult logistic conditions. We like to thank Anu Dudhia for providing the MIPAS Reference Forward Model and his help to include the HITRAN 2004 spectroscopic database. For providing other observation data for comparisons and retrieval 
support I like to thank Fabrizio Ravegnani and Vladimir Yushkov for the FOZAN data, Cornelius Schiller and the FISH-Team for the FISH data, Genrich Shur for the TDC data, and the ACE-FTS Team for the ACE-FTS data. The Atmospheric Chemistry Experiment (ACE), also known as SCISAT, is a Canadian-led mission mainly supported by the Canadian Space Agency and the Natural Sciences and Engineering Research Council of Canada. Last but not least we like to thank everybody, who provided technical support for the CRISTA-NF measurements and data analysis.

Edited by: Erkki Kyrölä

\section{References}

Allen, G., Remedios, J. J., and Smith, K. M.: Low temperature midinfrared cross-sections for peroxyacetyl nitrate (PAN) vapour, Atmos. Chem. Phys., 5, 3153-3158, doi:10.5194/acp-5-31532005, 2005.

Bernath, P. F., McElroy, C. T., Abrams, M. C., Boone, C. D., Butler, M., Camy-Peyret, C., Carleer, M., Clerbaux, C., Coheur, P.-F., Colin, R., DeCola, P., DeMaziére, M., Drummond, J. R., Dufour, D., Evans, W. F. J., Fast, H., Fussen, D., Gilbert, K., Jennings, D. E., Llewellyn, E. J., Lowe, R. P., Mahieu, E., McConnell, J. C., McHugh, M., McLeod, S. D., Michaud, R., Midwinter, C., Nassar, R., Nichitiu, F., Nowlan, C., Rinsland, C. P., Rochon, Y. J., Rowlands, N., Semeniuk, K., Simon, P., Skelton, R., Sloan, J. J., Soucy, M.-A., Strong, K., Tremblay, P., Turnbull, D., Walker, K. A., Walkty, I., Wardle, D. A., Wehrle, V., Zander, R., and Zou, J.: Atmospheric Chemistry Experiment (ACE): Mission overview, Geophys. Res. Lett., 32, L15S01, doi:10.1029/2005GL022386, 2005.

Cairo, F., Pommereau, J. P., Law, K. S., Schlager, H., Garnier, A., Fierli, F., Ern, M., Streibel, M., Arabas, S., Borrmann, S., Berthelier, J. J., Blom, C., Christensen, T., D’Amato, F., Di Donfrancesco, G., Deshler, T., Diedhiou, A., Durry, G., Engelsen, O., Goutail, F., Harris, N. R. P., Kerstel, E. R. T., Khaykin, S., Konopka, P., Kylling, A., Larsen, N., Lebel, T., Liu, X., MacKenzie, A. R., Nielsen, J., Oulanowski, A., Parker, D. J., Pelon, J., Polcher, J., Pyle, J. A., Ravegnani, F., Rivière, E. D., Robinson, A. D., Röckmann, T., Schiller, C., Simões, F., Stefanutti, L., Stroh, F., Some, L., Siegmund, P., Sitnikov, N., Vernier, J. P., Volk, C. M., Voigt, C., von Hobe, M., Viciani, S., and Yushkov, V.: An introduction to the SCOUT-AMMA stratospheric aircraft, balloons and sondes campaign in West Africa, August 2006: rationale and roadmap, Atmos. Chem. Phys., 10, 2237-2256, doi:10.5194/acp-10-2237-2010, 2010.

Dudhia, A., Morris, P. E., and Wells, R. J.: Fast monochromatic radiative transfer calculations for limb sounding, J. Quant. Spectrosc. Ra., 74(6), 745-756, 2002.

Dufour, G., Boone, C. D., and Bernath, P. F.: First measurements of CFC-113 and HCFC-142b from space using ACE-FTS infrared spectra, Geophys. Res. Lett., 32, L15S09, doi:10.1029/2005GL022422, 2005.

Engel, A., Bönisch, H., Brunner, D., Fischer, H., Franke, H., Günther, G., Gurk, C., Hegglin, M., Hoor, P., Königstedt, R., Krebsbach, M., Maser, R., Parchatka, U., Peter, T., Schell, D., Schiller, C., Schmidt, U., Spelten, N., Szabo, T., Weers, U., Wernli, H., Wetter, T., and Wirth, V.: Highly resolved observations of trace gases in the lowermost stratosphere and upper troposphere from the Spurt project: an overview, Atmos. Chem. Phys., 6, 283-301, doi:10.5194/acp-6-283-2006, 2006.

European Space Agency: PREMIER: Candidate Earth Explorer Core Missions - Reports for Assessment, ESA SP-1313(5), Mission Science Division, ESA-ESTEC, Noordwijk, The Netherlands, ISSN 0379-6566, 121 pp., 2008.

Fastie, W. G.: Ebert Spectrometer Reflections, Phys. Today, 4(1), 37-43, 1991.

Francis, G. L., Edwards, D. P., Lambert, A., Halvorson, C. M., Lee-Taylor, J. M., and Gille, J. C.: Forward modeling and radiative transfer for the NASA EOS-Aura High Resolution Dynamics Limb Sounder (HIRDLS) instrument, J. Geophys. Res., 111, D13301, doi:10.1029/2005JD006270, 2006.

Glatthor, N., von Clarmann, T., Fischer, H., Funke, B., Grabowski, U., Höpfner, M., Kellmann, S., Kiefer, M., Linden, A., Milz, M., Steck, T., and Stiller, G. P.: Global peroxyacetyl nitrate (PAN) retrieval in the upper troposphere from limb emission spectra of the Michelson Interferometer for Passive Atmospheric Sounding (MIPAS), Atmos. Chem. Phys., 7, 2775-2787, doi:10.5194/acp7-2775-2007, 2007.

Grossmann, K. U., Offermann, D., Gusev, O., Oberheide, J., Riese, M., and Spang, R.: The CRISTA-2 mission, J. Geophys. Res., 107(D23), 8173, doi:10.1029/2001JD000667, 2002.

Gordley, L. L. and Russell III, J. M.: Rapid inversion of limb radiance data using an emissivity growth approximation, Appl. Optics, 20, 807-813, 1981.

Hervig, M. E., Russell III, J. M., Gordley, L. L., Park, J. H., and Drayson, S. R.: "Observationa of aerosol by the HALOE experiment onboard UARS: A preliminary Validation”, Geophys. Res. Lett., 20(12), 1291-1294, 1993.

Hoffmann, L.: Schnelle Spurengasretrieval für das Satellitenexperiment Envisat MIPAS, Ph.D. thesis, University of Wuppertal, Wuppertal, Germany 2006.

Hoffmann, L., Kaufmann, M., Spang, R., Müller, R., Remedios, J. J., Moore, D. P., Volk, C. M., von Clarmann, T., and Riese, M.: Envisat MIPAS measurements of CFC-11: retrieval, validation, and climatology, Atmos. Chem. Phys., 8, 3671-3688, doi:10.5194/acp-8-3671-2008, 2008.

Hoffmann, L. and Alexander M. J.: Retrieval of Stratospheric Temperatures from AIRS Radiance Measurements for Gravity Wave Studies, J. Geophys. Res., 114, D07105, doi:10.1029/2008JD011241, 2009.

Hoffmann, L., Weigel, K., Spang, R., Schroeder, S., Arndt, K., Lehmann, C., Kaufmann, M., Ern, M., Preusse, P., Stroh, F., and Riese, M.: CRISTA-NF measurements of water vapor during the SCOUT-O3 Tropical Aircraft Campaign, Adv. Space Res., 43(1), 74-81, 2009.

Holton, J. R., Haynes, P. H., McIntyre, M. E., Douglass, A. R., Rood, R. B., and Pfister, L.: Stratosphere-Troposphere Exchange, Rev. Geophys., 33(4), 403-439, 1995.

Homan, C. D., Volk, C. M., Kuhn, A. C., Werner, A., Baehr, J., Viciani, S., Ulanovski, A., and Ravegnani, F.: Tracer measurements in the tropical tropopause layer during the AMMA/SCOUTO3 aircraft campaign, Atmos. Chem. Phys., 10, 3615-3627, doi:10.5194/acp-10-3615-2010, 2010.

Kiefer, M., von Clarmann, T., Grabowski, U., De Laurentis, M., Mantovani, R., Milz, M., and Ridolfi, M.: Characterization of MIPAS elevation pointing, Atmos. Chem. Phys., 7, 1615-1628, doi:10.5194/acp-7-1615-2007, 2007. 
Küll, V.: Dynamik und Photochemie in der Stratosphäre: Spurengasmessungen des CRISTA Experiments, Ph.D. thesis, University of Wuppertal, Wuppertal, Germany, 2002.

Kullmann, A., Riese, M., Olschewski, F., Stroh, F., and Grossmann, K.-U.: Cryogenic Infrared Spectrometers and Telescopes for the Atmosphere - New Frontiers, Proceedings of SPIE, 5570, 423432, 2004.

Kullmann, A.: Ein flugzeugetragenes kryogenes Infrarotspektrometer zur Fernerkundung klimarelevanter Spurengase im Tropopausenbereich, Ph.D. thesis, University of Wuppertal, Wuppertal, Germany, 2006.

Laube, J. C., Engel, A., Bönisch, H., Möbius, T., Worton, D. R., Sturges, W. T., Grunow, K., and Schmidt, U.: Contribution of very short-lived organic substances to stratospheric chlorine and bromine in the tropics - a case study, Atmos. Chem. Phys., 8, 7325-7334, doi:10.5194/acp-8-7325-2008, 2008.

Marshall, B. T., Gordley, L. L., and Chu, D. A.: BANDPACK: Algorithms for modelling broadband transmission and radiance, $\mathrm{J}$. Quant. Spectrosc. Ra., 52(5), 581-599, 1994.

Offermann, D., Grossmann, K.-U., Barthol, P., Knieling, P., Riese, M., and Trant, R.: Crypgenic Infrared Spectrometers and Telescopes for the Atmosphere (CRISTA) erxperiment and middle atmosphere variability, J. Geophys. Res., 104(D13), 16311-16325, 1999.

Offermann, D., Schaeler, B., Riese, M., Langfermann, M., Jarisch, M., Eidmann, G., Schiller, C., Smit, H. G. J., and Read, W. G.: Water vapor at the tropopause during the CRISTA 2 mission, J. Geophys. Res., 107(D23), 8176, doi:10.1029/2001JD000700, 2002.

Purser, R. J. and Huang, H. L.: Estimating effective data density in a satellite retrieval or an objective analysis, J. Appl. Meteorol., 32(6), 1092-1107, 1993.

Redelsperger, J.-L., Thorncroft, C. D., Diedhiou, A., Lebel, T., Parker, D. J., and Polcher, J.: African Monsoon Multidisciplinary Analysis, B. Am. Meteorol. Soc., 87(12), 1739-1746, 2006.

Remedios, J. J., Allen, G., Waterfall, A. M., Oelhaf, H., Kleinert, A., and Moore, D. P.: Detection of organic compound signatures in infra-red, limb emission spectra observed by the MIPASB2 balloon instrument, Atmos. Chem. Phys., 7, 1599-1613, doi:10.5194/acp-7-1599-2007, 2007.

Remedios, J. J., Leigh, R. J., Waterfall, A. M., Moore, D. P., Sembhi, H., Parkes, I., Greenhough, J., Chipperfield, M.P., and Hauglustaine, D.: MIPAS reference atmospheres and comparisons to V4.61/V4.62 MIPAS level 2 geophysical data sets, Atmos. Chem. Phys. Discuss., 7, 9973-10017, doi:10.5194/acpd7-9973-2007, 2007.

Riese, M., Preusse, P., Spang, R., Ern, M., Jarisch, M., Grossmann, K. U., and Offermann, D.: Measurements of trace gases by the Cryogenic Infrared Spectrometers and Telscopes for the Atmosphere (CRISTA) experiment, Adv. Space Res., 19, 563-566, 1997.

Riese, M., Spang, R., Preusse, P., Ern, M., Jarisch, M., Offermann, D., and Grossmann, K. U.: Cryogenic Infrared Spectrometers and Telescopes for the Atmosphere (CRISTA) data processing and atmospheric temperature and trace gas retrieval, J. Geophys. Res., 114(D13), 16349-16367, 1999.
Riese, M., Friedl-Vallon, F., Spang, R., Preusse, P., Schiller, C., Hoffmann, L., Konopka, P., Oelhaf, H., von Clarmann, T., and Hopfner, M.: GLObal limb Radiance Imager for the Atmosphere (GLORIA): Scientific objectives, Adv. Space Res., 36(5), 989 995, 2005.

Rodgers, C. D.: Inverse Methods for Atmospheric Sounding: Theory and Practice, World Scientific, Hackensack, New York, 2000.

Rothman, L. S., Jacquemart, D., Barbe, A., Chris Benner, D., Birk, M., Brown, L. R., Carleer, M. R., Chackerian Jr., C., Chance, K., Coudert, L. H., Dana, V., Devi, V. M., Flaud, J.-M., Gamache, R. R., Goldman, A., Hartmann, J.-M., Jucks, K. W., Maki, A. G., Mandin, J.-Y., Massie, S. T., Orphal, J., Perrin, A., Rinsland, C. P., Smith, M. A. H., Tennyson, J., Tolchenov, R. N., Toth, R. A., Vander Auwera, J., Varanasi, P., and Wagner, G.: The HITRAN 2004 molecular spectroscopic database, J. Quant. Spectrosc. Ra., 96, 139-204, 2005.

Schaeler, B. and Riese, M.: Retrieval of water vapor in the tropopause region from CRISTA measurements, Adv. Space Res., 27, 1635-1640, 2001.

Schroeder, S. E., Kullmann, A., Preusse, P., Stroh, F., Weigel, K., Ern, M., Knieling, P., Olschewski, F., Spang, R., and Riese, M.: Radiance calibration of CRISTA-NF, Adv. Space Res., 43(12), 1910-1917, 2009.

Shur, G. H., Sitnikov, N. M., and Drynkov, A. V.: A Mesoscale Structure of Meteorological Fields in the Tropopause Layer and in the Lower Stratosphere over the Southern Tropics (Brazil), Russ. Meteorol. Hydrol., 32, 487-494, 2007.

Spang, R., Hoffmann, L., Kullmann, A., Olschewski, F., Preusse, P., Knieling, P., Schroeder, S., Stroh, F., Weigel, K., and Riese, M.: High resolution limb observations of clouds by the CRISTANF experiment during the SCOUT-O3 tropical aircraft campaign, Adv. Space Res., 42(10), 1765-1775, 2008.

Stefanutti, L., Sokolov, L., Balestri, S., MacKenzie, A. R., and Khattatov, V.: The M-55 Geophysica as a Platform for the Airborne Polar Experiment, J. Atmos. Ocean. Tech., 16(10), 13031312, doi:10.1175/1520-0426, 1999.

von Clarmann, T.: Validation of remotely sensed profiles of atmospheric state variables: strategies and terminology, Atmos. Chem. Phys., 6, 4311-4320, doi:10.5194/acp-6-4311-2006, 2006.

von Clarmann, T., De Clercq, C., Ridolfi, M., Höpfner, M., and Lambert, J.-C.: The horizontal resolution of MIPAS, Atmos. Meas. Tech., 2, 47-54, doi:10.5194/amt-2-47-2009, 2009.

Weigel, K.: Infrared limb-emission observations of the upper troposphere, lower stratosphere with high spatial resolution, Ph.D. thesis, University of Wuppertal, Wuppertal, Germany, 2009.

Weinreb, M. P. and Neuendorfer, A. C.: Method to Apply Homogeneous-path Transmittance Models to Inhomogenous Atmospheres, J. Atmos. Sci., 30, 662-666, 1973.

Werner, A., Volk, C. M., Ivanova, E. V., Wetter, T., Schiller, C., Schlager, H., and Konopka, P.: Quantifying transport into the Arctic lowermost stratosphere, Atmos. Chem. Phys. Discuss., 9, 1407-1446, doi:10.5194/acpd-9-1407-2009, 2009.

Winker, D. M., Hunt, W. H., and McGill, M. J.: Initial performance assessment of CALIOP, Geophys. Res. Lett., 34, L19803, doi:10.1029/2007GL030135, 2007. 
Yushkov, V., Oulanovsky, A., Lechenuk, N., Roudakov, I., Arshinov, K., Tikhonov, F., Stefanutti, L., Ravegnani, F., Bonafe, U., and Georgiadis, T.: A chemiluminescent analyzer for stratospheric measurements of the ozone concentration (FOZAN), J. Atmos. Ocean. Tech., 16(10), 1345-1350, 1999.
Zoeger, M., Afchine, A., Eicke, N., Gerhard, M.-T., Klein, E., McKenna, D. S., Moerschel, U., Schmidt, U., Tan, V., Tuitjer, F., Woyke, T., and Schiller, C.: Fast in situ stratospheric hygrometers: A new family of balloon-borne and airborne Lyman photofragment fluorescence hygrometers, J. Geophys. Res., 105(D1), 1807-1816, 1999. 